Illinois State University

ISU ReD: Research and eData

Theses and Dissertations

$3-25-2020$

\title{
"It Doesn't Seem Like a Big Deal": A Media Ecology Analysis of Digital Teen Sexuality and Sexting Education
}

Allison Marie Metz

Illinois State University, allie1marie@gmail.com

Follow this and additional works at: https://ir.library.illinoisstate.edu/etd

Part of the Communication Commons

\section{Recommended Citation}

Metz, Allison Marie, "'It Doesn't Seem Like a Big Deal": A Media Ecology Analysis of Digital Teen Sexuality and Sexting Education" (2020). Theses and Dissertations. 1225.

https://ir.library.illinoisstate.edu/etd/1225

This Thesis is brought to you for free and open access by ISU ReD: Research and eData. It has been accepted for inclusion in Theses and Dissertations by an authorized administrator of ISU ReD: Research and eData. For more information, please contact ISUReD@ilstu.edu. 


\title{
“IT DOESN'T SEEM LIKE A BIG DEAL”: A MEDIA ECOLOGY ANALYSIS OF DIGITAL TEEN SEXUALITY AND SEXTING EDUCATION
}

\begin{abstract}
ALLISON MARIE METZ
100 pages

In the state of Illinois, any person in possession of sexually explicit photos of a minor, even if the subject is oneself, can be prosecuted as a felon for possession of child pornography and be required to registered as a sex-offender (705 ILCS $\S 405$ ). Concurrently, the recent trend of 'send nudes' depicts humorous ways to request the transmission of sexually explicit photos, increasing this act as a normative practice for young people (Bradford, 2018; Thomas, 2017). This trend is incongruent with Illinois statue (705 ILCS § 405) and school administrative policy about transmitting sexually explicit photos of a minor. The clash of environments - adolescents' use of digital media and adolescent romantic experiences, education, and state law- raises serious questions about tensions within our shifting digital age, particularly in relation to educational messages about sexting. Therefore, a media ecology approach is employed to explore the environments that compound to education related to adolescent digital interaction via smartphones. This study explores if students learn about sexting in school curriculum, and if so, what are the prevailing messages? A dual method approach triangulates a qualitative analysis of existing curriculum with student interviews. From this thematic analysis, themes emerged related to educational messages about sexting: social consequences, self-responsibility, avoidance, casual approach to education, and students' desire for greater information about sexting. All of which serve to promote relevant, student-centered sexting curriculum development.
\end{abstract} KEYWORDS: sexting, education, digital literacy, sexuality, curriculum, adolescent, teenager 
“IT DOESN'T SEEM LIKE A BIG DEAL”: A MEDIA ECOLOGY ANALYSIS OF DIGITAL TEEN SEXUALITY AND SEXTING EDUCATION

ALLISON MARIE METZ

A Thesis Submitted in Partial Fulfilment of the Requirements for the Degree of

MASTER OF SCIENCE

School of Communication

ILLINOIS STATE UNIVERSITY 
C 2020 Allison Marie Metz 
“IT DOESN'T SEEM LIKE A BIG DEAL": A MEDIA ECOLOGY ANALYSIS OF DIGITAL TEEN SEXUALITY AND SEXTING EDUCATION

ALLISON MARIE METZ

COMMITTEE MEMBERS:

Lauren Bratslavsky, Chair

John Hooker

Aimee Miller-Ott

Andrew Ventimiglia 


\section{ACKNOWLEDGMENTS}

I would like to thank my family for how they have empowered me over the years. To my parents, you have taught me the value of hard work and encouraged me towards prioritizing people over profession. To my sisters, you have strengthened me with your humor and 'realitychecked' my frustrations time and time again. To my enduring best friends, The Franklin Girls, you have been my sanity through all of school's (and life's) ups and downs. To my church family who are too many to name, I love you all deeply and am so, so thankful for the role you all have played in shaping who I am. To my delta family, I never thought a part time job would bring me a chosen family of such caring people. For 20 hours a week, you all have been there for me. Thank you.

I would be remiss to not extend my sincerest thanks to my professional colleagues and mentors. To all my dear friends and fellow GTAs in the basement of Fell Hall, together you encouraged me to constantly better my work in teaching and schooling. To Nicole Hughes-Liss and Sarah Grace Hall, I wouldn't have wanted to be a part of any other peer mentor family. You are both amazing instructors from which to learn. To Dr. Anna Wright, you motivated me in my pursuit of critical instruction and guided my growth as an educator. To Dr. and Dr. Simmonds, Cheri, you established my pedagogical foundation and Brent, you opened my eyes to media ecology. This project wouldn't exist without the two of you. To so many others in the School of Communication, I can't thank you enough for supporting me throughout my six years.

To my committee members, Dr. Andrew Ventimiglia and Dr. John Hooker, your expertise has contributed immensely to this project and my own understanding of media ecology. To Dr. Miller-Ott, your undergraduate research methods class was the reason I decided to pursue communication research long-term. I am confident that I would not have applied for my master's 
degree at ISU had you not given me an override into that class. Learning from you over these years has changed how I approach communication studies and academia as a whole. Finally, to Dr. Lauren Bratslavsky, I cannot offer enough gratitude for how you have shaped this project and transformed me through this process. Your detail-oriented refinement was so impressive and much, much needed. When it comes to this project, you are the wind beneath its wings. I have grown from your tutelage and am forever grateful for your mentorship. Thank you.

Most importantly, I must express my gratitude to all who graciously gave of themselves to have a voice in this project. To my sweet graduate friends who shared stories, relayed experiences, and contributed informational leads, you all helped build this study from an idea into a thesis. To all of the educators who willingly shared their curricula, you demonstrate selfless and influential instruction. To each student participant who valiantly spoke-up, I consider you my co-authors in this research endeavor. Thank you for wanting to have a voice. Thank you for sharing.

A. M. M. 


\section{CONTENTS}

Page

ACKNOWLEDGMENTS

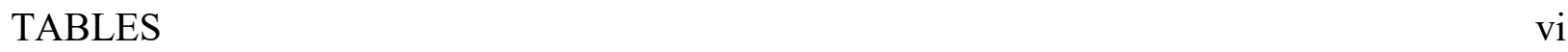

FIGURES Vii

CHAPTER I: INTRODUCTION 1

CHAPTER II: REVIEW OF LITERATURE 4

$\begin{array}{ll}\text { Ecological Framework } & 4\end{array}$

Profile of the Modern Teen $\quad 9$

$\begin{array}{ll}\text { Young Adult Romantic Experiences } & 10\end{array}$

Digital Complexities 11

Moral Panic and Teenage Romantic Experiences 15

$\begin{array}{ll}\text { Hookup Culture } & 17\end{array}$

$\begin{array}{ll}\text { Misrepresenting Adolescent Sexuality } & 18\end{array}$

The Teenager and the Institution of Education $\quad 19$

$\begin{array}{ll}\text { Education as a Moral Institution } & 20\end{array}$

Sex Negative Versus Sex-Positive Consequences 23

$\begin{array}{ll}\text { Digital Education } & 28\end{array}$

CHAPTER III: METHODOLOGY

Reflexivity 36

$\begin{array}{ll}\text { Procedure } & 36\end{array}$

$\begin{array}{ll}\text { Curriculum Analysis } & 37\end{array}$

$\begin{array}{ll}\text { Student Interviews } & 40\end{array}$ 
$\begin{array}{ll}\text { Participants } & 42\end{array}$

$\begin{array}{ll}\text { Data Analysis } & 43\end{array}$

Curriculum Analysis $\quad 43$

Student Interviews 45

CHAPTER IV: RESULTS 46

$\begin{array}{ll}\text { Curriculum Analysis } & 46\end{array}$

HECAT (Health Education Curriculum Analysis Tool) Results 46

$\begin{array}{lr}\text { Social Consequences } & 50\end{array}$

$\begin{array}{ll}\text { Cyberbullying } & 51\end{array}$

Low Policy Consequence $\quad 52$

$\begin{array}{ll}\text { Self-Responsibility } & 53\end{array}$

$\begin{array}{ll}\text { Cyberbullying } & 53\end{array}$

Online Predators 54

Student Interviews

"Avoid it at all costs"

"It wasn't something that the teacher put much emphasis on" 57

"I didn't even know it was illegal" 58

"Knowing all the facts would help tremendously" 58

$\begin{array}{ll}\text { CHAPTER V: DISCUSSION } & 60\end{array}$

$\begin{array}{ll}\text { Summary of Findings } & 60\end{array}$

$\begin{array}{ll}\text { Research Questions } & 60\end{array}$

$\begin{array}{ll}\mathrm{RQ}^{1} \text { and } \mathrm{RQ}^{2} & 61\end{array}$

$\begin{array}{ll}\mathrm{RQ}^{3} & 62\end{array}$ 
Messages About Sexting $\quad 62$

$\begin{array}{ll}\text { Social Consequences } & 62\end{array}$

Self-Responsibility 63

$\begin{array}{ll}\text { Avoidance } & 65\end{array}$

Casual Approach to Education 66

Desire for Increased Education 66

$\begin{array}{ll}\text { Implications of Findings } & 67\end{array}$

$\begin{array}{lr}\text { Practical Applications } & 69\end{array}$

$\begin{array}{ll}\text { Limitations and Future Research } & 72\end{array}$

$\begin{array}{ll}\text { Conclusion } & 74\end{array}$

$\begin{array}{ll}\text { REFERENCES } & 76\end{array}$

APPENDIX A: SOCIAL MEDIA RECRUITMENT MESSAGE 93

APPENDIX B: PARENTAL CONSENT FORM 94

APPENDIX C: PARTICIPANT INFORMED ASSENT 96

APPENDIX D: INTERVIEW PROTOCOL 98 


\section{TABLES}

Table

Page

1. HECAT Knowledge Expectation Coverage Score

2. Curriculum A HECAT Score

3. Curriculum B HECAT Score 48

4. Curriculum C HECAT Score 


\section{FIGURES}

Figure $\quad$ Page

1. Conceptualization of Ecology Framework Approach to Study 8

2. Conceptualization of Ecology Framework Approach to Methodology 34 


\section{CHAPTER I: INTRODUCTION}

[This project] is a look-around to see what's happening. It is a collide-oscope of interfaced situations (McLuhan, 1967, p. 10).

Some years ago, I was a teaching intern at a local high school. A few weeks into my appointment at this school, a fascinating event occurred. The Wi-Fi stopped working, particularly for every non-school issued device. While a router malfunction is, personally, not fascinating enough to warrant an entire thesis study, the administrator's purpose for intentionally turning off the Wi-Fi drew my attention to a larger phenomenon at hand: adolescent sexting and corresponding messages within their educational setting.

Students were using the school's network to transmit explicit photos. Upon being made aware of this issue, the school could be prosecuted as a willful and wanton accessory to the distribution of child pornography (720 ILCS $\S 5$ ). So, the administration stopped enabling Wi-Fi to personal devices. There were no accompanying messages, such as an assembly, instructional content about sexting, or even an announcement from the principle herself. Disabling technological access was the only message students received from their educational institution about sexting. While there was clearly concern with adolescent sexting, there was no confrontation at the conscious level related to this mediated interaction. How were students to realize the consequences, good or bad, related to their technological sexual interaction if educators were not instructing on this topic?

As I sat in a graduate seminar about media and technology, I noticed something curious when we read an article entitled, "Sex in the Digital Age: Media Ecology and Megan's Law" (Lunceford, 2010). In this piece, Lunceford explores the nature of sexting among adolescents by bringing to light the long-lasting and deeply affecting legal punishments for the transmission of 
explicit images among minors. In our class discussion, peers who were typically hesitant to speak were jumping in with stories that captured the complexities of sexting. Issues of legality and naiveté were prominent themes among these stories that were not so different from my own anecdote. Again, I had to ask, how were the teenagers of these stories to realize the consequences of sexting if they were never taught about mediated sexual interaction?

The next day, I shared this curiosity in the graduate teaching office. I was immediately met with more stories of the predicaments of sexting as a minor. Other graduate students peaked their heads around corners and pulled up chairs to insert their experiences into the conversation. It was the uncovering of so many personal or relational narratives that led me to believe there was something far greater going on. I am fully aware that an anecdote alone does not constitute much more than a slightly peaked interest; however, as the professor of that same graduate seminar, Dr. Simonds, reminded me, 'the plural of anecdote is data' (personal communication, 2019), and here, from my own experience as an educator and a discussion of sexting, was a plethora of anecdotes.

Thus, I began to probe deeper into the topic and was immediately confronted with even more stories of 'digital drama' (Thomas, 2018) in relation to sending and receiving sexually explicit photos among young adults. A growing proclivity of sexting as a flirtatious, gratifying, and normative relational aspect of the young adult experience alongside the viral popularity of the 'send nudes' trend are seemingly disconnected from the reality of some pronounced implications. The legal, personal, and social corollaries of sexting can be deeply affecting (Herman, 2010) and thus imperative for participants to grapple with. However, attitudes which write off teenagers as being addicted to digital technology and sexually deviant may limit the education available to this demographic, as I experienced some years ago as a teaching intern. 
But, any attempt to pass off this cultural shift would be in vain since sexting encompasses two, so far, unyielding realms: the adoption of the digital age and teenage sexuality.

However, as suggested in Lunceford's article (2010) and furthered from the personal testimony of my colleagues, there are some very serious consequences that adolescents incur when participating in sexting. Sexual interaction in a digital space for young people precipitates relational, social, and legal implications of which teenagers are all too often unaware when entering this participative space. I argue that more study should be paid to working with young adults to educate about the consequences, good or bad, of both sexual and digital activity to help sustain their changing culture within the legal and social constructs of the world around them.

The quote at the start of this chapter, from McLuhan's 1967, The Medium is the Massage, encompasses the foundation of this project. I seek to explore the collision between two significant areas of adolescent interaction, sexual and digital, to support my argument that sexting education is necessary to meet the needs of this adolescent digital practice. Each subsequent section contains an encapsulating quote from the preface of McLuhan's book that, together, exemplify the relevance of a media ecology study regarding sexting education for young adults.

First, I set the framework for this study by reviewing the significance of a media ecology approach and then move to profiling the modern teen. Here, I explore moral panic related to teen sexuality followed by a review of the institution of education, and more specifically, sexual and digital education. Then, I implement a multi-method research design to gather tangible, cumulating narratives of this intersection of adolescent sexting and education. Together, this study promotes increased relevant and student-centered sexting education for adolescents. 


\section{CHAPTER II: REVIEW OF LITERATURE}

The medium, or process, of our time - electronic technology - is reshaping and restructuring patterns of social interdependence and every aspect of our personal life. It is forcing us to reconsider and re-evaluate practically every thought, every action, and every institution formerly taken for granted. Everything is changing (McLuhan, 1967, p. 8).

I argue that education is the necessary, practical means to support adolescent digital sexual interaction in this new digital age. As McLuhan suggests, the world and the communication we are so familiar with are evolving with the adoption of digital technologies. Sexting is a prime context to explore how thought, action, and institution are shifting to create contentious spaces that leave students ill-equipped to understand sexual and digital interaction.

Here, I explore many of the compounding environments that relate to adolescent sexting education. The introduction of this technological interaction undoubtedly disrupts numerous contexts, many of which are subsequently reviewed. However, it is necessary to first situate this study in the framework of media ecology by discussing the philosophical significance of the technological interaction itself to then realize the socio-cultural waves created by sexting among adolescents as related to the institution of education.

\section{Ecological Framework}

It is impossible to understand social and cultural changes without a knowledge of the workings of media (McLuhan, 1967, p. 8).

Rather than an exclusive evaluation of the teen, the contents of the interaction, or the technology alone, we must first understand "the workings of media" through a media ecology framework. Media ecology suggests that we study these "complex communication systems as 
environments" (Nystrom, 1973 as cited in Strate, 2004). The environment established by our adoption of the digital age is "total and inclusive" (McLuhan, 1964, p. 57) such that humankind is bound by the new system and norms established thereby, and one cannot disconnect without grave social implications (Meyrowitz, 1985). It is not necessarily the technology itself that poses dangers, but that these digital tools encapsulate human interaction to a degree far greater than previously experienced. Therefore, media ecology can be understood as the study of how extensions of humankind afford and constrain the human experience. This approach seeks to bring about a realization of the interacting components that surround technologically mediated interaction, analyzing both the affordances and constraints indicative at each layer of this communication system that is young adults and sexting. As McLuhan's contemporary, Culkin, famously puts it, "we shape our tools and thereafter they shape us" (1967, p. 70).

In order to better situate this study in the media ecology realm, I must address some of the philosophical implications of our digital technological tool, the smartphone, and the significance of the image, particularly the sexual image. This way, we are better prepared to understand the role of sexting, the specific technological interaction, within this framework.

Both the affordances and constraints of digital media are apparent and often widely debated when it comes to the smartphone. On the one hand, interaction across the digital medium allows increased connection between users, establishing a 'global-village' wherein humankind is extensively intertwined through information ("Playboy Interview: Marshall McLuhan," 1969). The world, in many senses, becomes smaller as we share and gather more and more information about those with whom we would never connect outside of the digital realm. It increases our awareness of people and groups that were otherwise marginalized, such as teenagers, who due to digital media, "can no longer be contained ... they are now involved in our lives, as we in 
theirs" (McLuhan, 1964). Because of the smartphone, we are privy to the trends and tastes of this population. We are made aware of their viral 'send nudes' humor. We become unavoidably conscious of their involvement in sexting.

This increased awareness brought about from this digital medium promotes an encroachingly inclusive relationship with the user, the 'other hand' of this technological tool. As the smartphone connects individuals, it simultaneously demands interaction. Unlike the television, where the user watches from a distance and is delivered fully formulated entertainment, the smartphone requires that the user participate, to actively seek information. This is considered a cool medium (McLuhan, 1964). Here, the teenager makes deliberate decisions in relation to sharing and gathering personal or sexual information and images. Engagement in this cool space is neither numb nor passive. It is conscious interaction that requires a conscious solution. Cool medium interaction requires education.

In consideration of whether or not sexual images transmitted between teens through the cool smartphone medium are of even a remote epistemological value for study, I am compelled to address the ongoing ecological argument about the utility of the image itself. Some argue that the written word is and should remain the capture of academic attention (Postman, 1985) and thus, deem the exchange of sexual images between adolescents as a culturally depriving interaction. In a western culture that values the hot medium of the printed word (McLuhan, 1964), particularly the biblical printed word, many would agree. However, a history of iconcentric religion points to the opposite affect where numerous cathedrals are adorned with sexually charged depictions and even "the period when Christ is literate, when he can speak, is edited out of southern Catholicism" (Postman \& Paglia, 2007, p. 286). Here, we see that the cultural high point is the image itself. It is the image that divulges reality. Media ecologist 
Baudrillard agrees, asserting that "'images have become our true sex object, the object of our desire"” (1988 as cited in Lunceford, 2010, p. 242).

Thus, all of these tensions are at play when it comes to adolescent sexting. Through the technological tool of the smartphone, we have become connected to the teenage experience only to learn that they engage in sexting. We realize that the smartphone requires participation from teenagers and then recognize that this means they are actively seeking out sexual images. We hope to dismiss the utility of the sexual image as depraved only to understand the pervasive history of such depictions in our cultural values. Here is the contentious abyss, this disconnect between what we teach students about interaction versus the way students actually interact, explored by this study. These shifting tensions are not yet consciously addressed by those responsible for educating young adults, yet we promote technological adoption and instill grave penalties for digital impropriety. It is as though we are throwing adolescents the keys to the car without first teaching them how to drive. To reiterate Lunceford's (2010) probe, so long as these shifts are ignored ... we will continue to have laws that, through their unintended consequences, reveal the disconnect between what we think that we are, what we wish we were, and how we actually behave when we think that no one (or everyone) is watching (p. 243).

So, in an attempt to no longer ignore the tensions created by young adult sexting, I submit that education is key to addressing the gaps of uninformed adolescent digital sexual interaction. Students should not be left without education related to sexting when their school Wi-Fi is disabled. Therefore, I explore the educational messages related to sexting that are or are not present in school curriculum. But, first, I unpack certain complex environments that contribute to and are contrived by adolescent sexting. I begin by profiling the 'typical' adolescent. A 
discussion of the existing literature regarding young adult romantic experiences, the ensuing moral panic associated with hookup culture, and misrepresentations of teen sexuality will be useful in recognizing the messages compiling around sexting. Finally, we look into the moral foundation associated with the institution of education and the place of sexual education and digital education within this establishment.

This exploration is conceptualized as ripples from a stone cast into the water. If we consider the technological interaction of smartphone sexting to be the stone itself, the ripples are the impending influence on surrounding environments, which are all affected by the introduction of this new technological communication (Figure 1). The ripple metaphor suggests that all these environments are fluid and shifting yet all impacted by the stone. These environments include the individual or the technology user, the culture wherein the individual is situated, the institutions which frame culture. Going forward, I review literature related to the immediate environments disturbed by smartphone sexting, which culminate to the ripple at the outer banks - the educational messages about adolescent sexting.

\section{Figure 1}

Conceptualization of Ecology Framework Approach to Study, adapted from Vandewater (2013).

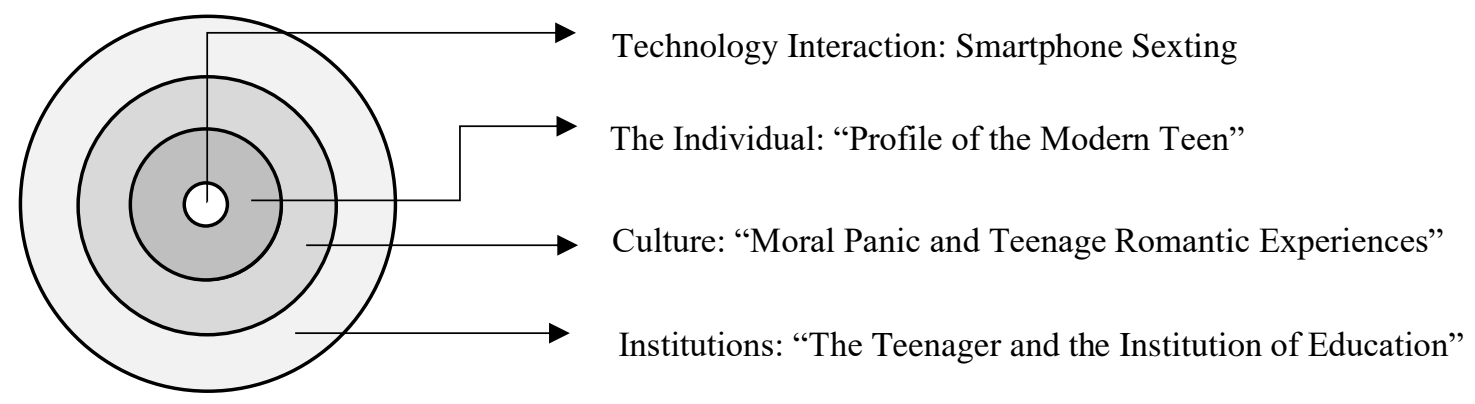


Again, it is imperative to recognize the fluidity of these environments. Each rippled layer is not rigid in its placement nor bothered by extending into other contexts. However, at each level, the ripples are all related to the initial introduction of the technological interaction sexting. Since the significance of sexting itself, the technology of the smartphone and the sexual image, are better realized in light of media ecology philosophy, I move to consider an immediate environment stirred up by sexting, which is the individual using the technology, the modern teen.

\section{Profile of the Modern Teen}

\section{Youth instinctively understands the present environment - the electronic drama} (McLuhan, 1967, p. 9).

Teenagers, defined as individuals aged 10-19 years old by the World Health Organization (WHO), make up approximately 17\% of the world population ("Coming of Age", 2019). The WHO stresses a need for continued understanding of and education for adolescent wellbeing, seeing that teenage years are highly formative times. During these years, 10-19-year old's move towards establishing new relationships, particularly romantic relationships (Choukas-Bradley, Goldberg, Widman, Reese, \& Halpern, 2015; Collins, Welsh, \& Furman, 2009; Furman, 2018; Galliher, Welsh, Rostosky, \& Kawaguchi, 2004); and, as easy as it is to define 'adolescent' by the specific age categorization, it is equally as challenging to define the terms of teenage sexual interactions (Furman, 2018). Varying degrees of relational or otherwise romantic interaction within this age group contributes to vague and complex meaning of 'teenage romance.' In this section, I address young adult romantic experiences and discuss the digital complexities that are associated with adolescent development. Essentially, in this section I unpack the 'electronic drama' associated with the teenage experience, particularly in relation to the digital sexual environment. 


\section{Young Adult Romantic Experiences}

The prevalence of sexual conversation as a taboo is a deeply-rooted construct for our American culture (Humphrey, 2016; Mitchell, 2014; Montemurro, Bartasavich, \& Wintermute, 2015). Disapproval towards an invitation to talk about sex is characteristic in American culture (Helpern, Ferraro, Werder, \& Mason, 2017; Humphrey, 2016; Kubica, 2006; Mitchell, 2014; Montemurro et al., 2015) Still, even more forbidden than a conversation about sex is to bring up the idea that adolescents are imperative yet currently uninvited participants in this conversation (Schalet, 2011). However, while we may continue to preclude adolescents from sexual conversation, they are not precluding themselves from sexual activity (Center for Disease Control, 2017).

Romantic relationships for adolescents most often refer to "mutually acknowledged ongoing voluntary interactions ... [having] a distinctive intensity, commonly marked by expressions of affection and current or anticipated sexual behavior" (Collins et al., 2009, p. 632). The distinction of mutual acknowledgement distinguishes teenage relationships from general romantic experiences, a term that encompasses a "broad range of experiences, emotions, and cognitions, including both those within and outside of particular relationships" (Furman, 2018, p. 411). This term includes non-reciprocated sexual attraction (crushes) and casual sexual interactions like hookups, which range from make-outs to intercourse (Collins et al., 2009). The term 'romantic experiences' covers a broader range of sexual interaction which is significant especially in the context of interactions in digital space. Thus, this study will focus on the holistic range of sexual interaction by utilizing the term romantic experience.

In the past, there have been broad attempts to halt any sexual activity among teens (Gresle-Favier, 2012). Still, many in this demographic continue to initiate romantic experiences 
(Furman, 2018), which are now largely mediated in the digital space ("Lessons in Love," 2017).

Since, as McLuhan (1964) puts it, the environment established by our adoption of the digital age is 'total and inclusive' (p. 57), this movement to interaction using digital technology is, likewise, inescapable.

\section{Digital Complexities}

A major aspect of romantic experiences for today's teens is the inclusion of digital technology as a significant medium (Baker \& Carreño, 2016). Authors of a Pew Research study (Anderson \& Jiang, 2018) found that of teens aged 13-17 years old, 95\% of this age group use a smartphone and $45 \%$ report almost constant use of this digital tool. As a reminder, our established adolescent population includes those as young as 10 years old, and while this may seem young, the national average for the age at which children receive their own smartphone is now 10.3 years old (“Kids \& Tech,” 2016). Still, many teens use social networking sites, the most popular being Snapchat (Anderson \& Jiang, 2018), as a means to initiate and perpetuate romantic experiences (Van Ouytsel, Va Gool, Walrave, Ponnet, \& Peeters, 2016).

While adolescents heavily use social network platforms regardless of existing romantic involvement, there is a high reliance on digitally mediated interaction as a significant tool for establishing romantic experiences. In fact, some schools are instilling educational curriculum aimed at teaching face-to-face communication skills for the purpose of initiating and carrying on romantic experiences outside of social media interaction (“Lessons in Love," 2017). Partner reconnaissance and relationships status broadcasting are the two dominate roles held by social media in teenage romantic experiences (Van Ouytsel et al., 2016), but the use of digital media for the purpose of sexting is also a rising practice for adolescents (Julian, 2018; Lee, 2018). 
Sexting holds numerous connotations and academics submit a variety of operational definitions, the broadest being "the transmission of sexual text or nude or sexual photographs via cellular smart phones" (Fortenberry, 2013, p. 176). However, this definition leaves much to the imagination in terms of the constitution of 'sexual.' Mitchell, Finkelhor, Jones, and Wolack (2012) conducted a survey in which participants flushed out this term to reveal that much of adolescent sexting included non-explicit images that featured covered or partially covered genitalia. Thus, sexual may not just entail explicit nudity but partial nudity. Likewise, sending and receiving a sext that is only text is less pertinent to focus of this study and this age group (Lenhart, 2009), and thus, this definition of sexting craves a more structured operationalization. Therefore, for the continuation of this paper, sexting will be defined as "creating, sharing and forwarding of sexually suggestive nude or nearly nude images" (p. 4), specifically in the context of smartphone communication.

The rising popularity of smartphone ownership for teenagers (Anderson \& Jiang, 2018; (“Kids \& Tech,” 2016) is consistent with an increase in sexting (Lee, 2018) a practice which many teenagers view as normative (Thomas, 2018). In 2009, Lenhart, with Pew Research Center, reported that of teenagers ages $12-17,4 \%$ had sent a sext and $15 \%$ had received a sext. In 2018 , authors of a study for JAMA Pediatrics reported that of teenagers younger than 18 , approximately $15 \%$ had sent a sext and $27 \%$ had received a sext and, interestingly, $12.5 \%$ said they have forwarded someone else's sext (Madigan, Ly, Rash, Van Ouytsel, \& Temple, 2018). The less studied population of teens ages 10-11 years old were the focus of a 2012 study wherein even $1 \%$ of this age group had sent or received a sext (Mitchell, Finkelhor, Jones, \& Wolack, 2012). Some studies suggest all of these numbers are even higher (Strassberg, McKinnon, Sustaíta, \& Rullo, 2010), particularly due to the concern of face-saving in many of these self- 
report scenarios (Lenhart, 2009; Madigan et al., 2018; Mitchell et al., 2012). As previously discussed, sexual activity is a taboo topic and sexting is often viewed as equally nefarious (Lenhart, 2009).

Digital sexual activity takes place in multiple relational contexts and sexting has been studied in committed and casual interactions. Within a committed, secure relationship, adults report positive relational consequences (Drouin, Coupe, \& Temple, 2017), suggesting that sexting is not always an illicit sexual activity and should not necessarily be written off as inarguably deviant since there may be some interpersonal benefits. On the other hand, the reports from casual romantic interactions and the adolescent demographic are not as constructive. In the same 2017 study, Drouin, Coupe, and Temple write that even their adult participants experienced increased negative consequences, particularly emotional consequences, with casual sexting. There is wide academic recognition of the negative correlation between sexting participation and mental health quality for teens (Strassberg et al., 2010). All too often, teens share explicit photos with one individual who then passes-along or posts these images beyond the sender's intended scope. In these cases, mental health and cyberbullying are of the utmost concern in regard to negative implications of teen sexting (O’Connor, Drouin, Yergens, \& Newsham, 2017). Thus, casual sexting among adolescents is not a highly reputed activity. Additionally, Pew Research Center reports that sexually explicit photos sent via text message in private, committed romantic relationships among those ages 12-17 was only one context that sexual activity occurred (Lenhart, 2009). The other two settings of sexting took place in casual contexts: "between partners that [share sexts] with others outside of the relationship and exchanges between people who are not yet in a relationship" (p.1). This means that a two-thirds of sexting interaction 
among adolescents occurs in contexts that are beyond the realm of positive sexting consequences (Drouin, Coupe, \& Temple, 2017) and occur in spaces that are not committed nor secure.

As previously mentioned, a specific phenomenon related to teens and digital interaction is the social media anecdote of the 'send nudes' trend. Themes of humor on social media and meme content ebb and flow based on socio-cultural trends, and one of those themes is requesting explicit photos by spelling out in various, and often humorous ways, 'send nudes'

(Maycolacerda, 2010). While it is difficult to describe the details of these viral videos and images in a way that does justice to the humorous context, it is the popularity of a video which requests nude images that reflects a greater underlying existence of the common place of asking for explicit photos (Bradford, 2018) and the corresponding pressure associated with such blatant requests (Thomas, 2017). In her content analysis of digital drama stories from 462 women (the most frequent sex to receive nude photo requests) with a median age of 15, Thomas (2017) concludes that "not all young women have the tools to say 'yes' or 'no' without consequences both internal (self-doubt and self-criticism) and external (social censure, mass distributed photographs, threats, and coercion)" (p. 204). Individuals trained in and information related to sexting education both serve as beneficial resources to equip young adults who sext, yet neither are commonplace as a means to assist adolescent technological interaction. Thus, if sexting among teens is a growing trend (Strassberg et al., 2010; Lenhart, 2009) and is conveyed as normative (Thomas, 2017), how is the surrounding ripple, which is the cultural environment, responding to such digital evolution for the new normative teenage romantic experience? The answer, unfortunately, is not one of empowerment but of panic over moral corruption and corresponding disappointing educational consequences. 


\section{Moral Panic and Teenage Romantic Experiences}

This is the reason for the great alienation between generations. Wars, revolutions, civil uprisings are interfaces within the new environments created by electronic informational media (McLuhan, 1967, p. 9).

Moral panics are pejorative attitudes about certain groups or behaviors resulting from sensationalized portrayal of those groups or behaviors as destructive to the established societal structures (Gresle-Favier, 2012). Historically and sexually speaking, moral panics have often been spawned by the realization of minority populations as sexually active (Hills, 2014) and tend to act as an attempt to suppress such activity (Elliott, 2012; Eversman \& Bird, 2017; GresleFavier, 2012). While sex among these marginalized groups may not be ground-breaking in terms of practice, a heightened representation, or misrepresentation, of this sexual occurrence in the mass media tend to alter attitudes about sex among these populations (Angelides, 2012; GresleFavier, 2012).

In the 1960s, the rise of feminism and the introduction of the oral contraceptive symbolized a rise in sexual promiscuity for women, particularly young women as perpetuated by the mass media's 'sexual revolution' narrative (Angelides, 2012; Brewitt-Taylor, 2017; Hills, 2014). For the 1980s, political rhetoric targeted teenage promiscuity as the driving factor in unwanted pregnancy and contraction of disease (Gresle-Favier, 2012), offering reason to frame sexual activity as deviant and even deadly (Eversman \& Bird, 2017; Gresle-Favier, 2012). Today, hookup culture acts a labeling term to describe the commitment-free nature with which teens approach sex (Garcia, Reiber, Massey, \& Merriwether, 2013). Such moral panic over the realization of sexuality among youth ("Coming of Age”, 2019), perpetuate the taboo of informative sexual conversation with adolescents (Schalet, 2011). 
Even as norms about sexuality shift, a persistent thread about teenage sexuality is the strong religious backdrop for suppression of sexual activity (Brewitt-Taylor, 2017; Mitchell, 2014). While the moral compass of Christianity, the Bible, does outline principles of abstinence (1 Corinthians 7:9; Hebrews 13:4 English Standard Version), it is particularly interesting that even the conversation, not just the act, of sex is viewed as perverse (Mitchell, 2014). However, sexually charged images, as depicted in many Christian cathedrals, and narratives are central to much of the Judeo-Christian religion (Postman \& Paglia, 2007). Thus, the juxtaposition of the sexuality woven throughout religious history versus the prominent avoidance of the slightest sexual immorality leaves this contentious abyss wherein the issues of privacy, information, and parental authority in relation to teen sex are heavily debated (Kubica, 2006) or simply ignored (Helpern, Ferraro, Werder, \& Mason, 2017). It is through this cultural contradiction that Elliott observes that "teenagers are deemed too young to know about sex, but too sexually driven to be trusted with information" (2012, p. 1).

The fact of the matter is teenagers do know more about sex than we like to believe. As, children's literature professor, Dr. Seelinger Trites pointed out to me in a class lecture (personal communication, 2015), if you consider how young you were when you learned about such 'inappropriate' things, it was probably much, much earlier than young adulthood. It was likely when you first set foot on the playground as a small child, if not before. As Dr. Seelinger Trites suggested to me this day in class, 'we like to think that children are innocent; they are not.' Just as so, as Elliott states (2012), there is a competing idea that teenagers are sexual maniacs who choose to engage in hookups without commitment, and much like the misconstruction that teens are "too young to know about sex" (Elliott, 2012, p. 1), the perceptions of wild engagement in hookup culture are equally as falsifiable. 


\section{Hookup Culture}

Hookup culture, a term which heightened in popularity in the past decade, refers to sexual interaction between individuals who have no intention to maintain a relationship (Monto \& Carey, 2014) and is largely associated with the sexual happenings on college campuses (Pham, 2017). Since this paper is aimed at addressing sexuality among adolescents, rather than college age adults, the conversation of collegiate hookups may seem beyond the scope of this topic. However, messages of hooking-up and having sex are plastered across the lifespan and cultivated through entertainment media like Teen Vogue (D’Amato, 2009), Seventeen Magazine (Madison, 2011), and many of the popular television shows targeted at a teenage audience (Eyal \& Finnerty, 2009; Garcia et al., 2013). Thus, the environment of messages about hookups which surrounds adolescents is significant when considering teen initialization of romantic experiences. By better understanding the sexual script of hooking-up, we can view the sexual interactions of young adults in a clearer light. Likewise, the moral panic over precarious teenage sexuality is heightened by the supposed irking of hookup culture (Pham, 2017).

A 'hookup' can be constituted by a multitude of various behaviors or interactions ranging from kissing to intercourse (D'Amato, 2009), but, according to Urban Dictionary, "when said by people ... it generally means to have sex" (Foreva, 2007). Participation in hookup culture, particularly on college campuses is often perceived to be an encouraged aspect of college life (Kerner, 2013). Progression in views of gender roles, increased acceptance of 'non-traditional' dating schemas, and engagement in party lifestyles are all suspected contributors to a rise in casual, uncommitted sex (Pham, 2017). Similarly, heightened viewership of sexualized media is correlated to an increased endorsement of hookup culture on college campuses among students (Aubrey \& Smith, 2016). Yet, Holman and Sillars (2012) found that students "greatly 
overestimated the pervasiveness of hookups within the general student culture” (p. 209), suggesting incongruence between messages of a proposed culture of rampant casual sex and actual rates of hookups. In an altogether different frame, yet with strikingly similar outcomes to moral panic, this 'pluralistic ignorance' (Pham, 2017) is not the complete understanding of young people's sexual attitudes and actions. Similarly, moral panic over the suspected rise of teenage casual sex with strangers has been prevalent in recent years (Garcia, Reiber, Massey, \& Merriwether, 2013; Monto \& Carey, 2014), but likewise, the statistics are not as holistically convincing (Julian, 2018; Manning, Longmore, Copp, \& Giordano, 2014; Monto \& Carey, 2014).

\section{Misrepresenting Adolescent Sexuality}

The Center for Disease Control reported that nearly $40 \%$ of teens, ages $14-18$, have engaged in sexual intercourse and 30\% describe themselves as having had sex within the past 3 months (2017). However, only 10\% reported having more than four sexual partners, a dramatic decrease from 1991 when 19\% of adolescents reported having more than four sexual partners. Likewise, Byers, O’Sulivan, \& Brotto (2016) found a growing number of young people are making active choices to refrain from sexual activity after having previously engaged, findings which "challenge common discourse around adolescent sexual norms" (p. 842). While cynicism of hookup culture abounds, teens are actually having less sex with fewer people and show no increased lascivious attitudes in recent years (Julian, 2018; Monto \& Carey, 2014).

However, I must point out the distinction in these trends, the decrease in sexual partners for teenagers, that may not be overtly apparent. Although adolescent physical intercourse is at a stagnant, if not lower, frequency, there is more to the teenage romantic experience that may be sexual in nature but not defined in the bounds of previous research (Manning et al., 2014). 
Penetrative intercourse is no longer the focus of adolescent sexual interaction (Fortenberry, 2013). Still the existing 'sexual script' of hookup culture (Monto \& Carey, 2014) and potentially fluid definitions of teenage relationships suggest there are broader implications to sexual activity and romantic interaction for adolescents (Manning et al., 2014). There is a multitude of assertions about the decline of casual sex among young people, especially when considered among the growing landscape of digital sexual tools available to adolescents (Julian, 2018; Strassberg, McKinnon, Sustaíta, \& Rullo, 2010). While suggesting reason after reason for young people's sexual shifting over time could certainly consume the remainder of this paper, it will be a better use of our time to continue examination of the environment related to the education, both sexual and digital, that is offered or not offered to teenagers from a historically moral institution.

\section{The Teenager and the Institution of Education}

Learning, the educational process, has long been associated only with the glum. We speak of the 'serious' student (McLuhan, 1967, p. 10).

In order to dig into this understanding, which can have deep seeded negative connotations for teenagers, it is important to discuss the history of education and the substantially rooted role of morality within this institution. Here, the response to adolescent moral infraction is often harsh and resolute such that the entire educational process tends to become "glum" and “"serious" for the teenage participant. Beyond this review of education's institutional history, the specific integration of sex-negative, rather than sex-positive, education, which is spurned by schooling's moral roots, is discussed. Next, I review various, but limited, integrations of digital literacy curriculum in public school curriculum to set the stage for this specific study of digital sexual education. 


\section{Education as a Moral Institution}

The place of Christianity as a driving force in moral panic over teenage sexuality is also foundational to education, particularly the institution of education in the United States. The first movements towards a collective practice of educating children was for fear of a demoralized society in the New World (McClellan, 1999). Puritan parents felt that the Devil would be best kept at bay if their children were able to read the Word of God and would include children in familial Biblical studies. As such, the growing practice to teach reading in homes to support religion was one of the factors that lead to more formalized and legally enforced methods of literacy training. The Old Deluder Act, referring to Satan's prowess to delude the minds of the

scripturally untrained, was the first public legislation that required students to attend schools for literacy training (Christakis, 2017). Early textbooks, called Primers, contained scripture and Christian ideology upon which children were tested (McClellan, 1999). As communities continued to grow, so did the need for more schools, and common across these institutions was the practice of strict discipline over both pupil's body and mind (Rousmaniere, Dehli, \& Coninck-Smith, 1997). When, in the 19th century, a rise in urbanization was associated with an increase in poorly disciplined children among the working class in the U.S., the breakdown of the family structure was blamed, and Charity Schools rose in popularity as a means to orient these children to the discipline of the established hierarchical structures of society (Nasaw, 1979). Soon, organized public schools acted as institutions of moral training for children of struggling families to whom the lure of free education would invite student enrollment (McClellan, 1999).

As public education progressed, a lessening of biblical influence was replaced with the conceptualization of an overarching moral education. Throughout the late 20 th century, religious 
morality was progressively replaced with educational teachings of pluralism, individualism, civic duty, and virtue ethics (Lee \& Taylor, 2013). Much of public-school moral curriculum deals in 'character education' which largely focuses on positive behavior as opposed to critical thinking about right and wrong (Kohn, 1997). This approach largely indoctrinates its pupils to revere conservative behavioral outcomes and is insistent on conformality (White, 2015). Beyond teachings of right and wrong in the classroom and offering rewards for positive behaviors (Kohn, 1997), rigorous discipline, similar in concept to that of Charity Schools, is implemented as a means to assert alignment with this character education.

Zero-tolerance policies enacted by secondary educational institutions are an attempt to eradicate misbehavior by adolescents (Teske, 2011). Historically, zero-tolerance was encouraged as a function of Bush's 1980s 'broken window,' war on drugs platform and typically punished violent and/or drug related behavior (Ward, 2014). The idea was to apply harsh consequences to any and all students who commit an offense so that a single student is removed from the system to not create more misbehavior and to act as a cautionary example for the remaining peers. However, many administrations have taken these policies to extend beyond the original intention of curbing violent behavior to now function as a moral policing of other less criminal misbehaviors (Teske, 2011). A review of zero-tolerance policies indicates that while school administrators intend for these policies to suppress further and more severe behavior, swift and unquestioned punishment is not an effective disciplinary approach in schools (Skiba et al., 2006) These policies tend to be broadly applied and predetermined so that missteps of differing severity, regardless of perpetrator history or situation, receive the exacting punishment.

Zero-tolerance policies are often implemented for instances of sexting in secondary public schools (Wood, 2010). Applying such policies to sexting perpetrations is just as futile and 
ineffective as the zero-tolerance policies for drug related and violent behavior (Wright, 2012). The concerning nature of zero-tolerance and sexting is that there are often long-lasting legal implications when administrators punitively punish the senders and recipients of these 'visual love-notes' (Leary, 2010; Wood, 2010).

Within the state of Illinois, any adolescent in possession of a digital photo of a nude or partially nude adolescent may be prosecuted for "disorderly conduct, public indecency, child pornography, a violation of Article 26.5 (Harassing and Obscene Communications) of the Criminal Code of 2012, or any other applicable provision of the law" (705 ILCS $\S 405$ ). Many of these listed prosecutions are felony charges, meaning there is no expunging of the record and depending on the outcomes of the case, the teen would be required to register as a sex offender (Herman, 2010). Additionally, the law makes no distinction regarding the subject of the photo. So, a teenager who has a nude or partially nude photo of themselves, stored on their personal device, could still be charged with possession of child pornography - certainly a substantial application of zero-tolerance.

While there are undoubtedly serious concerns with issues of cyberbullying or pressured participation in sexting, the unyielding discipline of zero-tolerance does not produce the best outcome for 'reforming' students away from sexting behaviors (Wright, 2012). Critics of zerotolerance suggest contextually focused disciplinary action for sexting (Wood, 2010), meaning administrators would determine punishment on a case-by-case basis. While this approach leaves much gray area for flexibility across administrative practices that could be argued and bent subjectively (Leary, 2010), this gray area may be necessary for students who are utilizing sexting as a natural tool for exploring sexual development (Wood, 2010). However, if this is the case, there is a serious need to first recognize how public schools view sexual exploration by their 
adolescent pupils so that measures for appreciating sexual activity in a digital context can or cannot be understood.

\section{Sex-Negative Versus Sex-Positive Consequences}

Moral education likewise extends to sexual education in public schools (Baker, Smith, \& Stoss, 2015). The issue of sex education involves the notion of abstinence-only versus comprehensive sex education: sex-negative attitudes versus sex-positive attitudes. Sex negative attitudes are defined in the Oxford Dictionary as "intolerant attitude[s] towards sex and sexuality" (Sex-Negative, 2019). Sex-negative attitudes are indicative of abstinence only or abstinence emphasis education, which in the 1980s became a government funded education program (Santelli et al., 2017) and again increased in funding in the 1990s (Barth, 2005). All of this funding of abstinence promotion was in hopes of reducing teen pregnancy and the transmission of STDs (Stanger-Hall \& Hall, 2011). Abstinence education, as outlined by the federal government, is curriculum defined by the following characteristics, including but not limited to a program which:

A) has as its exclusive purpose, teaching the social, psychological, and health gains to be realized by abstaining from sexual activity; ...

D) teaches that a mutually faithful monogamous relationship in context of marriage is the expected standard of human sexual activity;

E) teaches that sexual activity outside of the context of marriage is likely to have harmful psychological and physical effects; ...

G) teaches young people how to reject sexual advances and how alcohol and drug use increases vulnerability to sexual advances; and 
H) teaches the importance of attaining self-sufficiency before engaging in sexual activity (Social Security Act, 1996).

At this point, the earlier discussion of lower rates of teen sex in recent years (Julian, 2018) might initially indicate a correlation between abstinence education and decreased sex among teens, and I do not wish to make any assumption of causation between these correlated statistics; however, it is significant to point out that the two anticipated outcomes of the abstinence approach, lower rates of teen pregnancy and contraction of STDS, are not correlated (Huelskamp, \& Catalano, 2018; Stanger-Hall \& Hall, 2011; Thomas-Deveaux, 2018; Zalaznick, 2017). The 'dangerous' aspects of sexual activity among teens remain regardless of lower rates of intercourse, meaning that the adolescents who are engaging in sexual intercourse are not doing so safely. Yet, 28 states still have laws and policies indicating abstinence-only or abstinence emphasis education (Stanger-Hall \& Hall, 2011).

Not only is abstinence-only education not correlated to lowering visible consequences of teen sexual activity, there are larger implications which are not addressed in curriculum aimed at abstaining from sexual urges all together. It is important to point out that the above Social Security Act of 1996 does not operationalize or differentiate the utilized term of 'sexual activity,' suggesting that sexual exploration of any type outside of monogamy is not 'standard' and may "have harmful psychological and physical effects" (1996). Additionally, consequences of gender inequality (Thomas-Deveaux, 2018) and perpetuating rape culture due to victim blaming, highlighted by "[teaching] young people to avoid sexual advances" (Social Security Act, 1996), and misunderstandings of consent (Burnett et al., 2009) are additional and, might I add, sobering outcomes to non-holistic sex education. Thus, a comprehensive curriculum aims to address not 
just the use of contraceptive and STD reducing behaviors in relation to intercourse, but it also covers responsible and ethical sexual practices and exploration.

Sex positive attitudes normalize sexual development through communication about sexual health to destigmatize and reduce shame about sexuality (Sex Positive Approaches with Adolescents, 2019). Increased education regarding sexuality corresponds to initial implementations of comprehensive sexuality education (CSE). CSE is outlined by certain health concerned organizations, such as the United Nations (Haberland \& Rogow, 2015). A CSE curriculum includes:

1) A basis in the core universal values of human rights

2) An integrated focus on gender

3) Thorough and scientifically accurate information

4) A safe and healthy learning environment

5) Linking to sexual and reproductive health services and other initiatives that address gender, equality, empowerment, and access to education, social and economic assets for young people

6) Participatory teaching methods for personalization of information and strengthened skills in communication, decision-making and critical thinking

7) Strengthening youth advocacy and civic engagement

8) Cultural relevance in tackling human rights violations and gender inequality

9) Reaching across formal and informal sectors and across age groupings (United Nations Population Fund, 2014).

Many of these guidelines for sex education are likewise encouraged by the CDC as "characteristics of effective health education curriculum" (Center for Disease Control, 2019). 
Notably, the Illinois State Board of Education (ISBE) advises health educators to review the CDC's suggested outline (Illinois State Board of Education, n.d.). Although the ISBE does not require all Illinois public schools to follow a comprehensive sex education program, the law requires contraceptive instruction to be taught alongside abstinence education (105 ILCS $\S 5$ ). Beyond this legal stipulation, the state board requires little else be include for sex education.

To address concerns of health education and help define guidelines for effective instruction, the CDC developed a tool to assist with the initial analysis of sexual health curriculum called the Health Education Curriculum Analysis Tool (HECAT) (Center for Disease Control, 2012). The HECAT contains 10 modules that address different areas of health education, including Alcohol and Other Drugs, Healthy Eating, Mental and Emotional Health, Personal Health and Wellness, Physical Activity, Safety, Sexual Health, Tobacco, Violence Prevention, and Comprehensive Health Education. The Sexual Health module is of particular interest for this study, seeing that it outlines specific knowledge and skills expectations related to sexual health understanding. By using this tool to evaluate existing or proposed sexual health curriculum, the CDC is taking steps to help operationalize useful sexting education within the standards of a comprehensive, or even just less abstinences-only, sex education program.

Additionally, some schools choose to make their own moves towards implementing CSE. For example, a curriculum from a public-school district in western Illinois, one of the very few area schools with publicly available curriculum, includes early conversation about sexuality in the digital space (Macomb, 2014). In 7th grade, students first introduction to sex education begins with an analysis of 'mixed messages' of sexuality across media content. The initiation of critical thinking about presentations of sexuality in a digital space are aligned with CSE curriculum, guideline 6 (United Nations Population Fund, 2014). Further into their study of sex, students 
learn about contraceptive practices, behavioral and hormonal, and follow this topic with a study of healthy versus unhealthy relationships, which is then supported by learning about sexual abuse and survivor resources (Macomb, 2014). These lessons align with CSE curriculum guidelines 2 and 4 (United Nations Population Fund, 2014).

This school's implementation of a "comprehensive health education program" (Macomb, 2014, p. 10) is progressive in terms of educating students in greater depth than abstinence only, but still fails to address more relevant issues for teens such as sexting. Additionally, this district has an established, and publicly available, school policy section, entitled, "Administrative Procedure - Guidelines for Investigating Sexting and Sextortion Allegations” (Macomb, 2016). The document operationalizes each term in depth and details the necessary actions for administrators when investigating and disciplining students, while also explaining the legal implications for each 'level' of participation in sexting. Likewise, it includes resources for parents and students involved in the investigation process, even though some of these resources are fairly outdated, largely anecdotally driven, and rely on the 'just don't do it' narrative (MTV, 2010). Still, the administrative emphasis on sexting procedure coupled with the instructional progress with sex education, is a more explicit realization of relevant sexual practices for teens than many other area school districts.

Although an updated set of sexual education guidelines may seem to be the 'pie-in-thesky' key to increased enlightenment regarding sexual activity for adolescents, there are mixed reviews of the overt effectiveness of such curriculum (Haberland \& Rogow, 2015). However, the increased comprehensive nature of the above CSE characteristics are encouraging when considering young adults' use of digital tools for the purposes of sexual exploration. The emphasis on critical decision making and cultural relevance for sexual activity affords greater 
opportunity for educational coverage of sexuality in the digital space, whereas the 'don't do it' approach to all sexual activity and sexting, as suggested by abstinence emphasis education, is failing students educationally (Raghuram, 2019). A program manager for sexuality education at Advocates for Youth, McBride, argues that “it can't be comprehensive sex education if we're not talking about what's relevant to our young people, and sexting is a big part of that” ( 9 9).

Still, the existing messages that are often communicated about sexting, largely rely on fear and advocate for abstaining from sexting all together (Doring, 2014). With more than half of the United States teaching abstinence from sexual interaction (Stanger-Hall \& Hall, 2011), it is not surprising that teens do not communicate about sexting as a sexual activity (Doring, 2014). Regardless, $86 \%$ of adolescents do view childhood sexting (under the age of 18 ) to be a crime, which is accurate, according to most administrative and legal policies (Gewirtz-Meydan, Mitchell, \& Rothman, 2018; Woods, 2010). This means that while the scare tactics of sexting education seems to prevail, the current understanding of sexting as a form of sexual activity is not highly regarded or taught in public education. But, this is not all together surprising when considering that digital education is not a highly adopted educational topic and has few federal or state requirements for implementation in the classroom. However, in a highly mediated culture, digital education is a relevant educational topic to student learning and educational messages about sexting.

\section{Digital Education}

Media literacy is a term defined as "the ability to access, analyze, evaluate, and communicate messages in a wide variety of forms" (Aufderheide \& Firestone, 1993 p. 6). Although there are many media ecologist who do not appreciate that the semantics of the term 'media literacy' are still largely oriented on the printed word, Postman argues that the ideal 
means to educate and thus establish a media literate society involves a heavy focus on interdisciplinary study (Strate, 2017) rooted in strict literacy of the word (Postman \& Paglia, 2007). While Postman, as previously stated, values the word above the image, the push for greater literacy of written text coincides with this belief. However, scholars posit that since our current society is in the digital information age, a move towards studying the media themselves is imperative (Dewar, 1998; Hobbs, 2004).

This approach is based on the understanding that adolescents are, in fact, largely immersed and concerned with digital media. The increase in ownership of digital devices among adolescents and time spent texting or online (Lauricella, Cingel, Blackwell, Wartella, \& Conway, 2014) is indication of this cultural shift away from print. These media present information that students must be taught "how to view, listen to, and evaluate" (Palmer, 2014, p. 68). Much like teaching reading and writing as necessary components of active citizenship in a print society (Postman, 1985), analysis and evaluation of media is now an additional, vital part of citizenship in today's society (Hobbs, 2004). An education which focuses on first understanding the media responsible for distributing the information and then centering on the message itself is imperative to these critical, evaluative skills (Kesler, Tinio, \& Nolan, 2016). However, this task is not easy, considering the variety of media and the amount of information that is accessible by adolescents, as Michael Kapor suggests, it is similar to trying to drink from a fire hydrant (Palmer, 2014). Still, in consideration of the significance of media literacy for analytical citizenship in the digital society, the task of media education must be undertaken when realizing that such training has great implications for increasing pensive content curation across digital spaces (Kesler, et al., 2016) so that adolescents are able to make choices about media that are purposeful and deliberate (Palmer, 2014). 
However, the United States has been slow to incorporate curricular adjustments into public education for the purpose of adolescent literacy in the digital age (Wan \& Gut, 2008). The rise of 'fake news' as an indicator of adult ignorance of information in the digital space has increased impetus for student education (Hobbs, 2017) yet the widely adopted Common Core State Standards have few specific goals for achieving a media literate student population within a digital space (National Governors Association Center, 2010). Common Core English Language Arts standards address literacy in areas of reading, writing, speaking and listening, and language, but do not address digital literacy. Similarly, the Media Arts standards revolve around graphic arrangement and artwork production, independent from a holistic understanding of content curation. Since the ISBE requires public-schools to address these federally developed standards, there is little specific direction for implementing digital literacy in the classroom. Thus, additional organizations, such as the International Society for Technology in Education (ISTE) have formulated specific standards that can be implemented into existing curriculum as a means to support educated digital interaction and content curation (ISTE, 2016).

Most recently, HB4007 advanced in the Illinois House of Representatives to outline standards for appropriate online interaction. This bill was proposed by democratic state representative Maurice West. Through contact with Representative West's office staff, I learned that this bill was initially put forward by a northern Illinois constituent and reinforced with student expressions of sexting education concerns (personal communication, 2020). The bill is currently co-sponsored by 13 democratic and 2 republican state congressional members. While the bill, at this present time, is not yet an official mandate, it offers areas of exploration for sexting curriculum taught in public high schools. These areas of exploration are as follows: 
A) The possible consequences of sharing or forwarding sexually explicit or sexually suggestive photographs or images, videos, or text messages.

B) The identification of situations in which bullying or harassment may result as a consequence of sexting.

C) The possible long-term legal, social, academic, and other consequences that may result from possessing sexual content.

D) The importance of using the Internet safely and how sexting may pose a risk on the Internet.

E) The identification of individuals in school, such as a teacher, school social worker, or counselor, or in the community, such as a police officer or community leader, who may be contacted for assistance with issues, concerns, or problems.

F) The development of strategies for resisting peer pressure and for communicating in a positive manner (HB4007, 2019 and 2020).

Since these standards are not yet regulated by legislation, the aforementioned and other area schools do not have a curriculum specifically aligned to support explorations of digital literacy. Some schools offer additional resources for parents, students, and teachers to utilize (McLean County Unit District 5, 2019). Similar to the ISTE standards, these digital citizenship resources are created by external organizations and the district offers them as optional tools for instruction in the classroom.

Overall, the institution of state education has a storied past of moral enactment coupled with harsh disciplinary indictments, thus leading to neglect of progressive curriculum for both sexual and digital education. While zero-tolerance policies rooted in religious themes of abstinence, sexual or otherwise, come down harshly on teens who communicate through 'digital 
love notes' (Wood, 2010), there is limited formal education regarding sexual interaction within digital platforms.

From the placement of the digital sexual image within a philosophical media ecology framework, to the residual taboo of teen sexuality and their sexual knowledge, and the lack of education for sexual and digital interaction among adolescents, there are overarching messages about sexting inherent to the specific curriculum planned by and delivered within public schools, if present at all.

Related messages of teenage sexuality have historically been aggregated from ideals of innocence and misinformation about teen sexual practices. Moral panics that are incongruent with statistical tends of teen's sexual habits and attitudes across time and digital spaces, correspond to adult withholding of information that is imperative for knowledgeable teen sexual interaction. Likewise, the foundation of morality within institutional education and the resulting moral messages, or intentional non-messages, about effective sexual practice are significant to incurring more structured withholding of information or misinformation for teens and sexual education. Similarly, the harsh policy, both according to schools and the law, associated with sexual digital interaction suggest that compliance with legal standards should be a component of messages surrounding sexting within digital literacy education.

Now that we have intentionally explored these environments that contribute to the tensions associated with teenage sexting, it is imperative that we continue by questioning the specific existing, if existing at all, education that adolescence in public schools receive about sexuality, digital interaction, and the concurrent messages regarding sexting. So, the following research questions will guide this search into specific curriculum from schools in central Illinois about sexting and education for teenagers: 
$\mathbf{R Q}_{1}$ : Does the school teach sexual education, and if so, what are the prevailing messages, if any, about sexting?

RQ2: Does the school teach digital literacy, and if so, what are the prevailing messages, if any, about sexting?

RQ3: What in-school education, if any, do students use to form attitudes about sexting? 


\section{CHAPTER III: METHODOLOGY}

Our time is a time for crossing barriers, for erasing old categories - for probing around (McLuhan, 1967, p. 10).

The beauty of a media ecology approach for this study is its continued purpose for the research method and is thus conceptualized in the same manner as before (figure 2). Here, the media framework motivates an inductive process of research to best realize how each ripple culminates to the outer environment, educational messages about sexting. Just as before, the technological interaction, smartphone sexting, is the stone and each impending ripple is a different, but fluid, environment. Again, we start by questioning the individual. I ask students questions related to their personal attitudes about sexting. Next, to explore culture, I interview students about the immediate context around them, including perceptions of peer sexting, classroom instruction, and policy. Then, I look specifically at the institution by analyzing sexting curricula. Finally, these layered ripples culminate to an understanding of the institutional messages or the prevailing educational messages about sexting.

\section{Figure 2}

Conceptualization of Ecology Framework Approach to Methodology

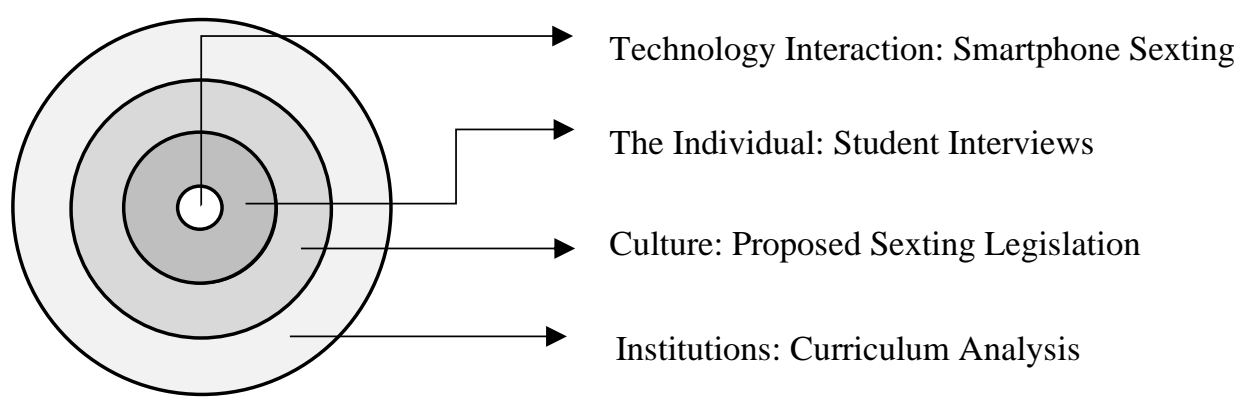


The ecology framework does not specifically guide my analysis but serves to support my implementation of an inductive qualitative, multi-method approach. Just as before, these environments are fluid and non-sequential. Thus, for the sake of effective time management in the research process, I conducted my curriculum analysis and then analyzed student interviews. Regardless, by employing this multi-method qualitative approach, the human experience as part of the complex communication system that is adolescent sexting and educational messages is more closely captured (Guba, 1978). Likewise, when considering educational purposes, a qualitative approach is essential for "disentangling causal relationships" and understanding the "many factors" that have a role in curriculum decisions (Ryan \& Hood, 2004, p. 84). Together, the human experience, or as is more appropriately titled for this study - the student experience, is essential to bolstering the initial curriculum analysis (Jensen, 2002).

This approach reflects a student-centered learning environment. In this pedagogical environment, the student is paramount to "assigning the meaning and relevance of learning" (Hannafin, Hill, Land, \& Lee, 2014, p. 641). Here, students glean the most knowledge and skills because they are the ones who have predetermined what is useful for learning. So, a curriculum analysis without the student perspective has the potential to yield a project that has no relevance to students and inevitably fails them in their sexting education. By incorporating the student voice in conjunction with existing sexting curriculum, the outcome is better oriented to have meaning and relevance for the student. Thus, the following chapter details the process by which existing sexting curriculum and student voices about sexting education culminate to bring clarity to the research questions. But first, I examine my role in this triangulation through a discussion of reflexivity. 


\section{Reflexivity}

As a researcher, I attempt to approach the process of questioning with as little subjectivity as possible. However, I must acknowledge my preconceived notions regarding public school curriculum, of both sex education and digital literacy-education, and my own experiences with messages of sexting from education. I am heavily immersed in social media and have seen first-hand the trend of 'send nudes' while also having numerous peers who sext using social media platforms, such as Snapchat or cellular texting. Additionally, the focus area of central Illinois public schools is important to discuss in light of reflexivity. Due to my physical location as a researcher within central Illinois, sampling area public school students is born out of convenience. However, as an alumnus of central Illinois public schooling, the review of literature was gathered from my foundational knowledge of education and policy related to sex education, digital literacy education, and sexting within these schools. Thus, the review of literature and the convenience sample are appropriately aligned for greater investigation.

Likewise, as an ISBE licensed high school educator, my existing opinions about the function and execution of 'effective' curriculum within public schooling are present. My professional thoughts towards child development and the role of sexual education and digital literacy education for adolescent growth are significant factors I recognize and contextualize in relationship to the curriculum analysis and my collection of interview responses.

\section{Procedure}

In line with my media ecology framework, the qualitative research design includes two main areas: thematic analysis of existing sexting curriculum triangulated with one-on-one student interviews. I first conducted a curriculum analysis, which served to produce a score for each curriculum, indicating the likelihood that students will master knowledge and skills 
expectations to increase healthy sexual behavior (HECAT, 2012, p. SH-1). Next, I employed a thematic analysis of the curricula and student interviews to search for overarching themes related to messages about sexting.

\section{Curriculum Analysis}

As reviewed in chapter two, the government has a role in institutionalizing the sexual health education taught in public high schools, as illustrated by the recently proposed HB4007 for the state of Illinois. In order to conceptualize the curriculum at hand, the surrounding legislative standard for education serves as a guideline. The areas of exploration proposed in HB4007, as previously outlined, are the standards to which public school curriculum may soon legally adhere. Thus, these areas of exploration directed my application of the Heath Education Curriculum Analysis Tool (HECAT).

The HECAT (Center for Disease Control, 2012) primarily guided the curriculum analysis. This tool was used to numerically assess curriculum. The resulting score indicates the coverage of relevant content for increasing healthy behaviors among students. The higher the score, the higher likelihood that students will master knowledge and skills necessary for practicing healthy behavior (p. SH-1). Specifically, I used the Sexual Health module because it was the most relevant for topics related to sexting. This module includes eight standards, each of which reflect an intended outcome for sexual health education. For example, standard 1 suggests that, "students will comprehend concepts related to health promotion and disease prevention" after learning from the curriculum in question. Then, within each standard, there are a number of unique knowledge or skills expectations that the sexual health curriculum should address, such as "evaluate the negative consequences of sending sexually explicit pictures or messages by e-mail or cell phone or posting sexually explicit pictures on social media sites" (SH1.12.6) - please 
note: numerical notations after each HECAT excerpt reflects the module title, standard, graduating grade level, and knowledge/skills expectation.

Since the HECAT Sexual Health module covers more than sexting, HB4007 helped to narrow my application of the curriculum analysis tool to assess only the expectations relevant to sexting education. Authors of the HECAT support this modification, saying "users are encouraged to review the analysis items before analyzing curricula and add, delete, or revise them to meet local needs and requirements" (HECAT, 2012, p. SH-1). The Illinois House bill proposes that sexting education includes coverage of consequences/risk/sexual risk behavior, bullying/harassment, policy (legal/academic), resources/individuals, and resisting peer pressure. In light of these terms from HB4007, only six standards were found relevant (standards 1, 2, 4, 5, 7, \& 8). The relevant standards cover student comprehension of concepts related to health promotion and disease prevention (standard 1), student analysis of the influence of family, peers, culture, media, technology and other facts on health behaviors (standard 2), student demonstration of the ability to use interpersonal communication skills to enhance health and avoid or reduce health risks (standard 4), student demonstration of the ability to use decisionmaking skills to enhance health (standard 5), student demonstration of the ability to practice health-enhancing behaviors and avoid or reduce health risks (standard 7), and student demonstration of the ability to advocate for personal, family, and community health (standard 8). The other two standards cover student's ability to access health care products (standard 3) and to set goals for preventing sexually transmitted disease and infection (standard 6). Neither is a skill promoted by HB4007 and both are less relevant to sexual experiences that occur exclusively in a digital space. 
Among the six standards used, a total of 25 knowledge and skill expectations were relevant for analysis. Some of these expectations included, "analyze the factors that protect one against engaging in sexual risk behavior" (SH1.12.9), "explain the influence of public health policies and state laws on sexual health practices, behaviors, and relationships" (SH2.12.1), and "predict potential short- and long-term consequences of alternatives of sexual health-related decisions" (SH4.12.6). It is important to note that it is apparent in the HECAT that curriculum can include a "combination of school-based materials, content, and events" (HECAT: Overview, 2012 , p. 4). Thus, all of the classroom materials sent to me from three local educators were analyzed under this definition of curriculum.

Three sexting education curricula were collected from email inquiry to three area public high school health instructors. I reached out to these particular school instructors because of my pre-interview student data related to where participants attend school and by recommendation from my university education librarian. My request for these materials was similar to journalistic inquiry and educators were under no obligation to offer access to these materials. However, all three instructors I contacted graciously shared their curriculum.

Each curriculum was labeled as curriculum A, curriculum B, or curriculum C. After using the Sexual Health module of the HECAT to determine a numerical value that reflects the amount of educational expectations met in the existing sexting curricula, I built upon this initial analysis to help search for emergent themes across the curricula. This enables a holistic approach to understanding not just a literal value associated with these classroom materials but reveals the themes that are or are not present within this established sexting education, which were then triangulated for analysis with the themes from student interviews. 


\section{Student Interviews}

The utilization of one-on-one interviews is imperative to collecting the learner perspective (Gubrium \& Holstein, 2003) of the received, or not received, sexting instruction. The "situated experiential realities" (p. 71) that students are enabled to convey through interviews in crucial to best understanding the young adult experience with the messages from their education, which alternative methods may not afford.

In order to recruit adolescent participants, I posted a social media message (see Appendix A for recruitment message) about the reasons for conducting the study and requested voluntary participation from high school students in central Illinois. This message was posted to Facebook and Instagram. My friends and followers were invited to share these posts on their own pages and feeds. Parents whose children were interested in participating in the study, accessed the parental permission form via a Qualtrics link included in the recruitment message (see Appendix B for parental consent form). After completing the parental consent form, parents entered their own email address. To this address, I sent an additional Qualtrics link which included the 14-17year-old informed assent and interview scheduling page. Parents were asked to share this link with their child. Upon accessing this link, potential participants read the informed assent document (see Appendix $\mathrm{C}$ for participant informed assent form) and then entered their school name and grade in school. Finally, this portal sent them to the interview scheduling page which also gave detailed instructions for accessing the online interview.

The one-on-one interviews were conducted through a secure digital platform, Zoom. The interviews were completed through this platforms' Chat feature, an instant messaging style of interaction. A mediating platform was necessary for these interviews to ensure confidentiality for young participants as well as comfortability to privately respond to potentially embarrassing 
topics (Bassett, Beagan, Ristovski-Slijepcevic, \& Chapman, 2008). Likewise, the Chat format was chosen as most useful for the participant demographic due to the increased use of messaging rather than verbal communication for adolescents (Lenhart, 2012) and the need for purposive, not representative, sampling of this demographic (Mann \& Stewart, 2003). During the interviews with participants, I utilized a semi-structured interview format that included, but was not limited to, a series of prewritten questions (see Appendix D for interview protocol). To prevent potential participant distress, I included a final Qualtrics link at the close of the interview. This link led participants to a portal in which they could pose anonymous questions to myself. This link also included phone numbers for counseling services for participants to contact should they experience any emotional distress from the interview.

Likewise, while the interview questions did not ask students to disclose their specific sexting practices, the private setting of digital interviews offered greater privacy for student disclosure of responses to questions related to the sensitive issue of sexting due to the connection of the interpersonal interview, as opposed to focus groups or face-to-face interviews (Lindlof \& Taylor, 2019). Each interview began with a statement of voluntary participation and a request for additional written consent to the interview. I pointed out that, 'I am hoping the student will be an equal partner with me to the findings of this research,' to establish a means towards fullest "selfexpression" (p. 238). The interview protocol was designed to last approximately 30 minutes, as young students could lose interest in long-winded questioning (Jacob \& Furgerson, 2012).

I established the protocol to first ask questions related to sex-education, with questions like, 'can you start by telling me what you remember most from your sex-ed classes at school?', 'what did your teacher in these classes tell you about sexting?', and 'pretend for a minute that you have just been chosen as the new teacher for a health class. What sorts of things would you 
teach your students?' I then transitioned to asking about digital training classes, if appropriate due to the semi-structured nature of the interviews. These digital training education questions included, 'has anyone at school ever taught you how to interact with others online?' and, 'what do you wish you would have learned about in your digital training classes?' Finally, I asked participants to reflect on their own attitudes towards sexting, asking 'imagine that your close friend told you that they were thinking about sending a sext. What would you say to them?' and, 'do you think that your classmates know that it is illegal to sext if you are under the age of 18? If so, how do you think they know this? If not, who do you think should tell them?' While these questions were included in the original IRB proposal, the semi-structured intention for the interviews enabled the 30-minute chat interviews to weave in and out of the pre-set questions. With the introduction of the Illinois House Bill, students were also asked what they thought this potential new education should include. The interviews were automatically transcribed and saved using the 'Save Chat' feature on Zoom.

\section{Participants}

I conducted five qualitative semi-structured digital chat interviews with adolescent students, ages 14-18, who are currently enrolled in public high school in central Illinois. Participants self-reported their grade in school as freshman $(N=2)$, sophomore $(N=0)$, junior $(N$ $=1)$, senior $(N=2)$, or other $(N=0)$. Twenty-one potential participants signed up for an interview time or partially completed the sign-up survey. However, 16 of these students did not report to the online chat room for their predetermined interview time or did not complete their appointment survey. Students with special needs and/or cognitive learning disabilities were not eligible to participate. Before any contact with prospective participants, I obtained IRB approval to conduct research with minors. Participants were not asked about their personal participation in 
sexting and were explicitly discouraged from sharing any personal engagement in sexting as a minor. Rather, I asked participants to respond to questions related to the messages about sexting from their school education and what messages of sexting from school informed their attitudes about sexting (see Appendix D for adolescent interview protocol). Participants were assigned pseudonyms.

\section{Data Analysis}

In order to effectively gain insight from both the curriculum analysis and participant interview, I utilized Braun and Clarke's (2012) "six-phase approach to thematic analysis" (p. 60). The overarching process for thematic analysis of both the curricula and interviews is described in this section followed by details of analysis for each individual data set. I first conducted my curriculum analysis and then my student interview analysis.

\section{Curriculum Analysis}

To be able to apply the HECAT: Module SH, Sexual Health Curriculum (CDC, 2012) to my three existing sexting curricula, the areas of exploration presented in HB4007 were used to determine which HECAT standards were relevant to use for analysis. For standard 1, 10 knowledge expectations were assessed. In standard 2, 4 of the skills expectations were assessed. Standard 3 was not assessed. For standard 4, 4 skills expectations were assessed. In standard 5, 3 skills expectations were assessed. Standard 6 was not assessed. In standard 7, 1 skill expectation was assessed. For standard 8, 3 skills expectations were assessed. Then, each of the relevant knowledge or skills expectations were assessed in each curriculum. The HECAT yields a numerical score which corresponds to the level of material covered in the educational resource (Table 1). 


\section{Table 1}

HECAT Knowledge Expectation Coverage Score

\begin{tabular}{lll}
\hline$\%$ & Quantity Label & HECAT Score \\
\hline $100 \%$ & All of the skills expectations & 4 \\
$67-99 \%$ & Most of the skills expectations & 3 \\
$34-66 \%$ & Some of the skills expectations & 2 \\
$1-33 \%$ & A few of the skills expectations & 1 \\
$0 \%$ & None of the skills expectations & 0 \\
\hline
\end{tabular}

After using the HECAT to gain an overarching perspective of each curriculum's sexting material coverage, I implemented a thematic analysis across all three curricula. The first step of my thematic analysis began with familiarizing myself with the data (Braun \& Clarke, 2012). I read and re-read all three curricula and interview transcripts. I also reviewed my field notes and then began to develop preliminary codes for both data sets. For this phase, in the curriculum analysis I underlined concepts that were relevant to the HECAT. Next, I highlighted commonality in the curricula brought out by the HECAT. This helped to develop initial themes. Once I wrote these initial themes in my research notebook, I compared these notes to the data set in order to fully review, and in some cases combine, the now emergent themes (Braun \& Clarke, 2012. Next, I gave titles to the themes that helped to define each theme as independent and significant. Finally, I recorded my results in the following chapter.

After applying the HECAT and completing my thematic analysis for the three curricula, I followed the same process of thematic analysis (Braun \& Clarke, 2012) for the student interviews. 


\section{Student Interviews}

After conducting each one-on-one chat interview via Zoom, I saved the transcript of the interview to a secured computer file. I began by reviewing these transcripts numerous times. Next, I marked words or phrases the stood out as interesting or related to other interviews. Then, I made note of similar statements made across the interview transcripts. Once I had the visual representation of words or phrases present throughout the data, I reviewed and reorganized these groups to create initial themes. I then labeled these themes. Next, I compared the categories to the whole of interview data to check how these themes aligned to student interviews. Then, I wrote these results in Results chapter of this report. 


\section{CHAPTER IV: RESULTS}

When two seemingly disparate elements are imaginatively poised, put in apposition in new and unique ways, startling discoveries often result (McLuhan, 1967, p. 10).

I identified five themes related to educational messages of sexting during my data analysis. I found two primary themes from my analysis of existing sexting curriculum and three significant themes from student interviews. These themes were social consequences, selfresponsibility, avoidance, a casual approach to education, and desire for increased education. Before revealing the data that supports the emergence of these themes, I explain the results of the HECAT as part of my curriculum analysis.

\section{Curriculum Analysis}

The following section details the results of my thematic analysis for the three sexting curricula in question. These themes are social consequences and self-responsibility. Before surveying the details and subthemes of these two themes related to messages about sexting, below are the results of the HECAT. Then, the details of my thematic analysis of the three curricula follows.

\section{HECAT (Health Education Curriculum Analysis Tool) Results}

Each curriculum was analyzed using the HECAT Sexual Health module. I analyzed the curricula one at a time and determined the HECAT Knowledge Expectation Coverage Score (Table 1) for each of the six standards. Then, I averaged the six scores to determine the overall HECAT Score for each curriculum.

Each curriculum was a Google Slides presentation that consisted of text, images, and video attachments. Curriculum A consisted of 27 slides and included two classroom activities related to online interaction. This curriculum was sent to me from the school media resource 
instructor (librarian), who teaches this curriculum, entitled 'Digital Citizenship,' as a two-day lesson for each freshman health class. According to the HECAT, this entire educational resource averages a Knowledge Expectation Coverage Score of 2.83 (Table 2).

\section{Table 2}

\section{Curriculum A HECAT Score}

\begin{tabular}{|c|c|c|c|c|}
\hline Standard & Students will... & $\begin{array}{l}\text { \# Expectations } \\
\text { Addressed in Curriculum }\end{array}$ & $\begin{array}{l}\text { \# of Expectations } \\
\text { Assessed by HECAT }\end{array}$ & $\begin{array}{l}\text { HECAT } \\
\text { Score }\end{array}$ \\
\hline 1 & $\begin{array}{l}\text { comprehend concepts related to health } \\
\text { promotion and disease prevention }\end{array}$ & 6 & 10 & 2 \\
\hline 2 & $\begin{array}{l}\text { analyze the influence of family, peers, culture, } \\
\text { media, technology and other facts on health } \\
\text { behaviors }\end{array}$ & 2 & 4 & 2 \\
\hline 4 & $\begin{array}{l}\text { demonstrate the ability to use interpersonal } \\
\text { communication skills to enhance health and } \\
\text { avoid or reduce health risks }\end{array}$ & 3 & 4 & 3 \\
\hline 5 & $\begin{array}{l}\text { demonstrate the ability to use decision-making } \\
\text { skills to enhance health }\end{array}$ & 1 & 3 & 1 \\
\hline 7 & $\begin{array}{l}\text { demonstrate the ability to practice health- } \\
\text { enhancing behaviors and avoid or reduce health } \\
\text { risks }\end{array}$ & 1 & 1 & 4 \\
\hline 8 & $\begin{array}{l}\text { demonstrate the ability to advocate for personal, } \\
\text { family, and community health }\end{array}$ & 3 & 3 & 4 \\
\hline
\end{tabular}

For standard 1, curriculum A addressed consequences, contributing factors, means for protection, and potential harassment when it comes to sexting/sexual risk behavior. Curriculum A did not, however, cover education regarding relational responsibility or respecting sexual behavior differences. In standard 2, curriculum A explained the role of peer pressure and other potential influence for engagement in sexting but did not explain the specific policies related to sexting. For standard 4, curriculum A demonstrated how to manage personal information online and offered a hotline for assistance with online predators. Curriculum A did not address peer resistance. For standard 5, curriculum A pointed out consequences of sexting but did not cover decision making as an individual or within a group/relationship when deciding to whether or not to sext. In standard 7, curriculum A helped students evaluate personal behaviors that reduce 
sexual risk behavior/sexting. For standard 8, curriculum A includes an opportunity for students to design a message that informs peers about consequences of sexting.

Curriculum B consisted of 69 slides and included four classroom activities related to online engagement. This curriculum was sent to me from a school health instructor, who teaches this curriculum, entitled 'Digital Citizenship,' in her freshman health classes. According to the HECAT, this entire educational resource, likewise, averages a score of 2.83 (Table 3).

\section{Table 3}

Curriculum B HECAT Score

\begin{tabular}{|c|c|c|c|c|}
\hline Standard & Students will... & $\begin{array}{l}\text { \# Expectations } \\
\text { Addressed in Curriculum }\end{array}$ & $\begin{array}{l}\text { \# of Expectations } \\
\text { Assessed by HECAT }\end{array}$ & $\begin{array}{l}\text { HECAT } \\
\text { Score }\end{array}$ \\
\hline 1 & $\begin{array}{l}\text { comprehend concepts related to health } \\
\text { promotion and disease prevention }\end{array}$ & 5 & 10 & 2 \\
\hline 2 & $\begin{array}{l}\text { analyze the influence of family, peers, culture, } \\
\text { media, technology and other facts on health } \\
\text { behaviors }\end{array}$ & 2 & 4 & 2 \\
\hline 4 & $\begin{array}{l}\text { demonstrate the ability to use interpersonal } \\
\text { communication skills to enhance health and } \\
\text { avoid or reduce health risks }\end{array}$ & 3 & 4 & 3 \\
\hline 5 & $\begin{array}{l}\text { demonstrate the ability to use decision-making } \\
\text { skills to enhance health }\end{array}$ & 1 & 3 & 1 \\
\hline 7 & $\begin{array}{l}\text { demonstrate the ability to practice health- } \\
\text { enhancing behaviors and avoid or reduce health } \\
\text { risks }\end{array}$ & 1 & 1 & 4 \\
\hline 8 & $\begin{array}{l}\text { demonstrate the ability to advocate for personal, } \\
\text { family, and community health }\end{array}$ & 3 & 3 & 4 \\
\hline
\end{tabular}

For standard 1, curriculum B addressed consequences, contributing factors, means for protection, and potential harassment when it comes to sexting/sexual risk behavior. Curriculum B did not, however, cover education regarding relational responsibility or respecting sexual behavior differences. In standard 2, curriculum B explained the role of peer pressure and the influence of certain regulations that contribute to engagement in sexting but did not explain the specific policies related to sexting. For standard 4, curriculum B demonstrated how to manage personal information online and offer support to peers online. Curriculum B did not teach students about a hotline for reporting online predators. For standard 5, curriculum B pointed out 
consequences of sexting but did not cover decision making as an individual or within a group/relationship when deciding to whether or not to sext. In standard 7, curriculum B helped students evaluate personal behaviors that reduce sexual risk behavior/sexting. For standard 8 , curriculum B includes an opportunity for students to design promotional pieces about the dangers of sexting.

Curriculum $\mathrm{C}$ consisted of 104 slides and included three classroom activities. While there was a large sum of educational information within these slides, only 10 were relevant to this topic of analysis. Many of these slides focused on mental, emotional, or sexual health, but the chosen 10 slides were the only materials that referenced any sort of digital interaction. This curriculum was sent to me from a school health instructor, who teaches this curriculum, entitled 'Mental/Social Health,' in her freshman health classes. According to the HECAT, this entire educational resource averages a score of 0.67 (Table 4).

\section{Table 4}

\section{Curriculum C HECAT Score}

\begin{tabular}{|c|c|c|c|c|}
\hline Standard & Students will... & $\begin{array}{l}\text { \# Expectations } \\
\text { Addressed in Curriculum }\end{array}$ & $\begin{array}{l}\text { \# of Expectations } \\
\text { Assessed by HECAT }\end{array}$ & $\begin{array}{l}\text { HECAT } \\
\text { Score }\end{array}$ \\
\hline 1 & $\begin{array}{l}\text { comprehend concepts related to health } \\
\text { promotion and disease prevention }\end{array}$ & 7 & 10 & 3 \\
\hline 2 & $\begin{array}{l}\text { analyze the influence of family, peers, culture, } \\
\text { media, technology and other facts on health } \\
\text { behaviors }\end{array}$ & 0 & 4 & 0 \\
\hline 4 & $\begin{array}{l}\text { demonstrate the ability to use interpersonal } \\
\text { communication skills to enhance health and } \\
\text { avoid or reduce health risks }\end{array}$ & 1 & 4 & 1 \\
\hline 5 & $\begin{array}{l}\text { demonstrate the ability to use decision-making } \\
\text { skills to enhance health }\end{array}$ & 0 & 3 & 0 \\
\hline 7 & $\begin{array}{l}\text { demonstrate the ability to practice health- } \\
\text { enhancing behaviors and avoid or reduce health } \\
\text { risks }\end{array}$ & 0 & 1 & 0 \\
\hline 8 & $\begin{array}{l}\text { demonstrate the ability to advocate for personal, } \\
\text { family, and community health }\end{array}$ & 0 & 3 & 0 \\
\hline
\end{tabular}


For standard 1, curriculum $\mathrm{C}$ addressed consequences, contributing factors, means for protection, potential harassment, and importance of setting boundaries when it comes to sexting/sexual risk behavior. Curriculum $\mathrm{C}$ did not, however, cover education regarding relational responsibility or respecting sexual behavior differences. In standard 2, curriculum C did not explain the role of peer pressure, other potential influence for engagement in sexting, nor cover specific policies related to sexting. For standard 4, curriculum $\mathrm{C}$ demonstrated how to manage personal information online but did not offer ideas for peer resistance or numbers to contact useful helplines. For standard 5, curriculum $\mathrm{C}$ did not address any decision-making skills related to sexting. In standard 7, curriculum $\mathrm{C}$ does not help students evaluate personal behaviors that reduce sexual risk behavior/sexting. For standard 8, curriculum $\mathrm{C}$ does not offer an opportunity for students to promote safe sexting practices.

Overall, these results reveal that both curriculum A and B already meet some, and close to most, of the knowledge/skills expectations proposed by the sexting curriculum legislation. Both curricula scored an average of 2.83 for their knowledge expectation coverage score. Curriculum $\mathrm{C}$ meets close to none of the knowledge/skills expectations, averaging a HECAT score of 0.67 .

\section{Social Consequences}

Across the curricula, consequences of sexting are tied to the social impact of a student's online presence. The curricula stress the potential repercussions with other students or older, non-student individuals who may be intended or unintended recipients of sexting images.

Curriculum B clearly promotes this message with slide notes informing students that " $88 \%$ of the self-made sexual or suggestive images that teens post online are re-posted to adult websites" and “posting these [pictures] online could: ruin your reputation.” Curriculum C includes a similar 
slide, stating "a negative online reputation ... can impact college admissions, employment, and other areas of life." This discussion of reputation as a broad social consequence is furthered by two additional subthemes: cyberbullying and few mentions of policy consequences.

Cyberbullying. The most apparent social consequence taught in school curriculum is cyberbullying. Each curriculum includes numerous slides related to cyberbullying and spends time defining where and how this harassment occurs. Testimonial videos for in-class viewing relate to students becoming socially isolated or targets of peer attacks for their sexting behavior. Curriculum A, B, and C all include a video made by Amanda Todd, a young girl who created this video as her suicide note in 2012. Teachers share Amanda's heartbreaking story of the ongoing harassment she endured over her shared explicit photos. To me, this video speaks most significantly to a need for increased resources and support for students who have already shared explicit images online or are, for any other reason, being cyberbullied. However, this video is used to again highlight the social misfortune of a sexting circumstance. Curriculum B notes, "people may bully or judge you because of the image. Some teens have been bullied so badly because of sexting that they have been afraid to go to school." Here, the bullying and judgement are taught to be potential issues for attending school, a regular social function, and not taught as concerns about mental health or lacking resources.

Likewise, curricula stress the potential for breaching confidentiality with explicit images that are shared beyond the intended recipient. "Cyberbullying Tactics" (curriculum C) are taught as actions that invade privacy by sharing personal information or embarrassing photos/videos. However, the interaction whereby this unwanted sharing occurs is not fully addressed. By this, I mean that there are very, very few mentions of sexting, and forwarding of sexts, as a part of unhealthy adolescent romantic experiences. The curricula do not cover the likelihood that 
cyberbullying stems from one partner sharing sexts with those who are outside of the relationship (Lenhart, 2009). Additionally, the focus on the social consequence of cyberbullying as most prominent is encouraged by the lack of depth regarding policy consequences of sexting for those under the age of 18 .

Low Policy Consequence. Despite the emphasis for social repercussions of sexting, there is very limited inclusion of policy consequences, school or legislative, regarding sexting among minors. This only encourages the importance of social rather than legal consequences. No curriculum addresses the school policy for students who sext nor offers direction for where this policy can be located. The legal policy for sexting, especially for those under the age of 18 , is not of high significance in the existing curriculum. Curriculum A includes the statement, "if you can get in trouble in real life, you can get in trouble online." This is problematic for many students who are almost certainly unaware of laws related to the physical distribution of child pornography. While the principle of this statement may be to encourage students about the reality of digital interaction, that the online realm is not a different world, it is vague in its translation for policy consequences. In curriculum B there is a more narrow detailing of potential penalties, pointing out that "some teens have been suspended from class, sports teams, and other activities." Still, the consequential emphasis lies in the potential for social distancing rather than legal outcomes. This curriculum does go on to specify that students sending explicit photos could face trouble with the law and be "charged with a crime and [have] to complete community service or educational programs." Again, this is incredibly vague in light of the potential for a felony charge to result from sexting interaction (Herman, 2010; 705 ILCS § 405).

Interestingly, while the curricula do not address policy related to sending sext messages, they also make no reference to the potential penalty for possession of explicit material. The 
curricula point out the possibility of becoming a victim of cyberbullying, and as previously mentioned offer numerous details related to cyberbullying, but they do not offer in depth discussion related to consequences for perpetrators who forward sexts or use personal images as a means for cyberbullying. Zero-tolerance of such action is passively mentioned, but no detailed information is shared regarding policy at the school or societal levels. Students who perpetrate cyberbully may gain a poor reputation themselves (curriculum C) or may hurt the feelings of their target (curriculum A). Yet again, the statement is vaguely applied, suggesting "if it could get you in trouble in real life, it could get you in trouble online" (curriculum B). Rather than clarifying the specific punishment for online harassers, the curricula focus on the steps students can take to prevent victimization in recurring calls towards self-responsibility when it comes to digital interaction.

\section{Self-Responsibility}

Student responsibility is explicitly brought out in existing sexting curriculum. The role of the student in preventing and reporting potential danger online is recurrently emphasized. For example, all three curricula direct self-responsible questions or phrases to students, such as “what can you do?" (curriculum A), "how are you representing yourself?" (curriculum B), and "protect yourself from cyberbullying" (curriculum C), which all place the burden for safe digital interaction on the individual student. Also, students are given a hotline number to call if they suspect they are interacting with an online predator (1-800-THE-LOST). Together, these two areas of concern, cyberbullying and online predators, for student digital interaction are included in the curricula as messages of self-responsibility.

Cyberbullying. Discussed frequently in high school curricula, cyberbullying is referred to again in the context of self-responsibility. In the previous theme, cyberbullying acts a subpoint 
in the 'bad outcomes' message of social consequences. Here, the educational materials suggest that students, not only have to fear being bullied as a social consequence, but they should be the ones protecting themselves from online bullying. Much of the curricula offer up potential means for self-preservation related to information or personal photos. Messages and activities related to social media TMI (too much information) and inappropriate content dissemination are present. Additionally, if students are already experiencing cyberbullying, they are encouraged to follow these guidelines that are a part of both curriculum A and B:

Ignore and block the bully. Offenders often want attention. Take it away and they may give up.

Save the evidence. You may need it later for documentation.

Change your privacy settings. Allow only people you trust to see or comment on your pages.

Tell trusted friends and adults. Create a support network.

Curriculum $\mathrm{C}$ outlines very similar suggestions but also includes the adage, "always think about what you post." Across all three curricula, it is up to the student, who may already be a target of harassment, to save or protect themselves from the harm of those they face online.

Online Predators. The flip side of this prevention message is encouragement towards reporting. Students are taught characteristics of online predators and offered phone numbers and websites for reporting predatory interaction. However, as previously mentioned, there is little information in the curricula that helps students understand how these cases will be handled or if reporting will be in any way fruitful. Regardless, the education again supports the idea that it is up to the student to take responsibility for identifying and reporting potentially dangerous individuals. Curriculum B even includes an activity where students are given a lineup of faces 
and asked to determine who looks like a stereotypical online predator. According to the slide notes, this activity is designed to help students recognize that there is no stereotype for predators. This activity serves as an eye-opening educational tool for students when it comes to recognizing dangers online. Yet, each curriculum fails to include local resources or professionals who can help students who are already experiencing cyberbullying or interaction with a potential predator.

\section{Student Interviews}

From student interviews, three themes emerged related to messages about sexting. Educational messages related to sex, internet use, and sexting emphasized risk and stressed avoidance. Instruction was approached casually and lacked detailed information. Finally, and maybe most significant for moving forward, students voiced a desire for increased, more clear sexting education.

\section{"Avoid it at all costs"}

Avoidance emphasis regarding sex, internet use, and sexting is a predominant educational message. Students express an understanding of risks associated with participation in any of these activities. Sexual education hinges on discussions of disease and infection as well as pregnancy. As Jordan, a high school freshman, pointed out, They didn't strictly preach abstinence, but it was hinted at that it was the best practice... it was mainly when they were talking about STIs/STDs. After every few sentences they would toss in the idea that abstinence is the only way to protect yourself from those and unplanned pregnancies. - please note: numerical notations after each excerpt reflects interview number and transcript line numbers (2: 25-26, 34-37). 
Emma echoed this sentiment, saying "we didn't really talk a whole lot about sex. Just that in order not to get pregnant to avoid it at all costs" (3:23-25).

In the same vein, internet use was also regarded as a risky behavior from the student perspective, although not as avoidant oriented as sex. Education about online interaction includes cautionary advice, such as "how to never trust everyone online and never share personal information" (Blair, 1: 67-68), and stresses the "need to be careful especially since colleges and jobs can look at your various social media accounts" (Emma, 3: 64-65). Chadwick, a senior, pointed out that much of the education about online interaction emphasized concerns of "cyberbullying along with how to safely communicate with people you may or may not know" (4: 24-25). While the risks of communicating online are significant to digital literacy education, it is an education of safe interaction, or being "smart about what you post" (Emma, 3: 61), not necessarily total avoidance.

However, that message once again shifts back to totally refraining when it comes to sexting. Here the risk emphasis, although not an in-depth education, is less about advice for safe interaction and pushes the importance of avoiding sexting participation all together. Chadwick explained how educators highlight the permanence and non-private nature of online sharing. Although it may feel confidential, there are still risks, obviously, that come with sexting and it can really change how people perceive you if this information was to get out ... if you wouldn't send it to your grandparents, then don't send it to anyone ... why would you want to send something to someone that you wouldn't want anyone else to see (4: $37-39,61-62,63-64)$.

Similar to education of sexual interaction, the negative "consequences of sexting" (Jordan, 2:47) are stressed in educational messages. While positive consequences of sexting for adolescents in 
insecure or noncommitted relationships are few (Drouin, Coupe, \& Temple, 2017), the interesting note found from the student perspective is a lack of resources or advice for students who may already participate in sexting.

\section{"It wasn't something the teacher put much emphasis on"}

Students all expressed their educator's casual approach to sex education, digital literacy, and sexting. This is not a reflection on the teaching style of the instructor but rather the content itself. Students reported feeling that 'sensitive' topics, like sharing explicit photos, were glossed over, mentioned in a passing comment, or not taken seriously. There was little detail or specific information related to sex, digital literacy, or sexting, and often the content about sexting was outsourced to guest speakers or online videos. Lucy, a high school junior, highlighted this laissefaire approach numerous times when recounting her experience. When I asked if anyone at school had ever taught her how to interact with others online, she explained, "not at school, no. Certain websites are blocked and you hear advice like don't go onto sites you don't know, but the only people who 'taught' me anything about online interaction was my parents" (5: 25-28). When I inquired about her sexting education, she voiced a similar experience, saying "I have a faint memory of learning what sexting is, but I'm not sure if that happened in health class or a book that I was reading" (5: 37-39). Jordan mentioned that sexting was mentioned "very briefly . . more like a comment that the teacher made" (2: 40-41) and Chadwick offered that "it wasn't something the teacher put much emphasis on" (4: 29-30).

Beyond the use of only casual mentions of sexting, students explained how this same casual attitude was rampant among peers when it comes to health education and their general feelings towards sexting. Lucy revealed that "a lot of the kids in [her] health class saw the class

and the teacher as a joke" (5: 88-89). Not only do students seem unfazed by their education from 
instructors, they are casual about their digital actions. "The term 'sending nudes' and other related things are thrown around so casually at school and online that it doesn't seem like a big deal" (Blair, 1: 82-83). This sort of unbothered attitude may not seem uncommon for teenagers, but when considering the very real potential for legal consequences, this informal approach about sexting is quite counterintuitive.

"I didn't even know it was illegal.” The casual approach to sexting education is apparent in students lack of knowledge about both the academic and legal policy for students who choose to sext. Teachers are not treating this education with the equal weight of the policies used to prosecute these interactions. Students could potentially be categorized as felons and register as sex offenders, yet few know about this potential outcome of their actions. I asked Chadwick if he thought his peers aware of the illegal nature of sexting as a minor, he says:

I would say that they know that but they don't comprehend that it actually is illegal. The reason I would say that is because I think more people my age think about something that's illegal and they start to think more along the line of major crimes (4: 52-55). By leaving out education of legal implication, the weight of potential sexting consequences is perceived as non-major, the exact opposite of potential charges. Lucy did not even recognize this potential consequence, revealing “I didn't even know that it was illegal. I just thought it's bad for your life" (5: 75-76). Likewise, students are overwhelmingly in the dark about their school policy for sexting, few knowing where to even locate the guidelines for this policy.

\section{"Knowing all the facts and consequences would help tremendously"}

Regardless of the risk emphasis and casual messages from existing sexting curriculum, students voiced a desire for increased education. As previously reinforced, students are often perceived as too young to be trusted with information (Elliott, 2012). But, student voices express 
a desire to learn and know about the societal implications of their own actions. When asked if there were any more questions or comments to be shared, Jordan responded:

I would just like to say that I know not everyone knows the right decisions for themselves, and they'll act without thinking. That and the fact that we have such easy access to technology are probably why sexting is such a big deal. With the proper education, people would be able to make the best decisions for themselves (2: 102-106). Proper education is a broad term, but other students suggested that just "knowing all the facts and consequences would help tremendously" (Emma, 3: 80-81) or that "a lot of the danger is not understanding what sexting is ... [and] it would be better to learn form a wise source than influential friends" (Lucy, 5: 43-45). Students want detailed information about sexting so that they are informed to interact in a space wherein they spend so much time.

To briefly summarize these findings, the existing sex education and digital literacy education contains multiples themes related to sexting. Educational materials emphasize social consequences and self-responsibility. From this curriculum, students learn a need to avoid sexting while recognizing that teachers approach this topic casually. Still, students express a desire for more accurate and detailed education about sexting. 


\section{CHAPTER V: DISCUSSION}

Survival is not possible if one approaches his environment, the social drama, with a fixed, unchangeable point of view (McLuhan, 1967, p. 10).

The purpose of this study was to explore adolescent sexting education by assessing existing curriculum and empowering student voice to uncover messages about sexting from school education. In the following discussion I address my specific research questions, the emergent themes, and survey significant implications and practical applications of this study. As the quote from McLuhan suggests, my intention in this discussion is to reveal new points of view about this specific topic of adolescent sexting so that new education is able to survive in such an evolving environment.

\section{Summary of Findings}

In summary, I conducted a thematic analysis from the existing sexting curricula and semi-structured student interviews from which five themes emerged related to messages about sexting. These themes were social consequences, self-responsibility, avoidance, casual approach to education, and desire for increased education. By presenting these themes in light of the guiding research questions, I was able to better explore the messages about sexting from sex education, from digital literacy education, and as informant for student attitudes.

\section{Research Questions}

Here, I address the initial findings related to my guiding research questions. These questions include, does the school teach sexual education, and if so, what are the prevailing messages, if any about sexting? Does the school teach digital literacy, and if so, what are the prevailing messages, if any, about sexting? And, what in-school education, if any, do students use to form attitudes about sexting? 
In the following subsection, I discuss the results to the first half of $\mathrm{RQ}_{1}$ and $\mathrm{RQ}_{2}$ : does the school teach sexual education and does the school teach digital literacy. Then, I address RQ3 and the overall attitudes about sexting from students. Following this, I address the second half of RQ1 and $\mathrm{RQ}_{2}$ as well as the specific school education referred to from $\mathrm{RQ}_{3}$ in my discussion of the emergent themes from my curriculum and interview analyses. Refer to the below section "Messages About Sexting" for more information regarding such themes.

$\mathbf{R} \mathbf{Q}_{1}$ and $\mathbf{R} \mathbf{Q}_{2}$. Sexting education is the place where sex education and digital literacy education meet. It is apparent from my collection of curriculum and student interviews that area schools are indeed educating students about sex and digital literacy but the distinction between the two subjects is no longer clear. Much of the digital literacy information is taught in light of health education, which also covers sex education. Even the future of this education is slotted to be intermingled, as proposed by HB4007. When I inquired about why sexting education was going to be incorporated as a part of sex education, a staff member from Representative West's office replied that sex education "just seemed like the best place for it" (personal communication, 2020).

The results of my analysis reveal that those responsible for the in-school education have already intertwined these two subject areas. For instance, when I ask a local high school health teacher for the sexting curriculum used in his class, he directed me to the school's Instructional Media Center (IMC) teacher. As the school's digital literacy resource, she is the one responsible for teaching the sexting curriculum as a part of sex education for all freshmen. Here, these two teachers pull from their individual expertise to teach sexting as a combined effort of sex education and digital literacy education. 
RQ3. When it comes to student attitudes about sexting, it is clear that the perpetual negative messaging is forefront in their own opinions. Students are fearful about sexting and have poor perceptions of students who sext or consider participating in sexting. Each student expressed sentiments about how bad' it is to sext and how it 'can ruin your life,' yet few were able to point to the specific policies that would actually incriminate a student for sexting. This means that much of the negativity placed on student engagement in sexting stems from peers who are perpetually taught to fear this digital sexual interaction. Negative attitudes relate to the negative messages that are abundant in existing sexting curriculum, which promotes social consequences and self-responsibility when it comes to adolescent sexting.

\section{Messages About Sexting}

The following themes represent the significant areas of sexting curriculum and student attitudes that were present in the data. While some themes emerged from either the curriculum or the interviews, all themes were consistently extant in both curriculum and student expression. These themes reflect the messages about sexting that are communicated in school education and then internalized by student learners.

Social Consequences. The findings of this project highlight the significant messaging related to social consequences of sexting. In both sex education and digital literacy education, the potential ramifications of sexting are largely tied to negative perception from peers or others who might learn of a student's participation in sexting. The potential for cyberbullying or sexual harassment from those online is emphasized as a primary outcome of digitally sharing explicit photos.

Students' attitudes about sexting were largely tied to this message. Fears of social outcasting or unintended exposure ruining their professional chances were common in student 
interviews. However, the legal consequences were not known. This is not all together surprising considering that the social lives of adolescents are of primary personal concern during these formative years (Choukas-Bradley, Goldberg, Widman, Reese, \& Halpern, 2015; Collins, Welsh, \& Furman, 2009; Furman, 2018; Galliher, Welsh, Rostosky, \& Kawaguchi, 2004) and a focus on this in education provides cognitive relevance for student learning. Still, this resounding emphasis on negative social consequences neglects the seriousness of policy implications, lessening student understanding about the potential legal ramifications of sexting.

A serious approach is not to be confused with increased negative education. After all, unsuccessful abstinence only education (Huelskamp, \& Catalano, 2018; Stanger-Hall \& Hall, 2011; Thomas-Deveaux, 2018; Zalaznick, 2017) is largely rooted in intolerant, or negative attitudes about sexuality (Sex-Negative, 2019) and much of sexting education is already teaming with fear appeals (Doring, 2014). There is certainly no shortage of negative messaging when it comes to student sex education. However, the continued instilment of a zero-tolerance approach from school administration and the legal system in relation to underage sexting demands that students, at the very least, be aware of the harsh punishment their actions could incur. If teachers are not sharing this information with students, there is an entire piece of this puzzle being left out so that teens are unable to have a clear picture of all that their digital sexual encounters could entail. Even more frightening than an unawareness of these policy consequences, is learning that most students have no idea of where they can search out details related to their school sexting policy regarding their potential legal infringements.

Self-Responsibility. Another recurring message in sexting education is the importance for students to take responsibility for their own actions, both sexually and digitally. In light of the review of literature, this message has two primary functions. First, a message of self- 
responsibility hands over a level of autonomy to the student, marking them as old enough to be trusted to make effective decisions. This is beneficial for students who, when handed technological tools, are being told they have control to interact in this space. It is an empowering message to offer adolescents who are all too frequently neglected from significant cultural information (Elliott, 2012). However, the second function of self-responsibility boarders on abandonment. The lack of resource allocation, or just resource recognition, within sexting education is astounding.

Victim blaming is a serious implication of some abstinence only or abstinence emphasis curricula that place the responsibility for negative impact on the initial decision of the student (Social Security Act, 1996). When students face harsh consequences, social or legal, from sexting, the blame is then place on the student's poor decision making, not on the perpetrator. When it comes to bullying or online harassment, the conversation is tied to student misbehavior. Mentions of hotlines for assistance with harassment is not enough to viably support the growing number of students who send or receive sexts, willing or not (Madigan, Ly, Rash, Van Ouytsel, \& Temple, 2018).

Students were told over and over about the importance of making good decisions when it comes to not engaging in sexting in the first place, but it was never mentioned what students could do if they were already participating in sexting. Regardless of the reasons for student engagement in sexting, those who want to stop or participate more safely are not currently given the tools to do so. If a message of self-responsibility is to be disseminated within high school education, then students need to be afforded resources for how to be self-responsible at every level of sexting participation, not just avoidance. Additionally, there is not enough discussion related to student action for receiving unwanted sexts or requests for sexts. When sexting, 
adolescents are frequently doing so as a normative function of the teenage romantic experience (Lenhart, 2009; Maycolacerda, 2010; Thomas, 2017); however, this is not widely addressed in curriculum. When not given the tools to navigate this complexity of a young interpersonal relationship, students are oriented towards complete avoidance of any similar behavior.

Avoidance. When considering the nomenclature for this theme, I originally label this avoidance message as abstinence. However, when reviewing the data, it was apparent that this term 'abstinence' is not often used by educators designing the curriculum nor in student reference. Rather, the term 'avoid' was used most frequently in sexting education and this is significant.

The prolonged tension over abstinence only or abstinence emphasis education (StangerHall \& Hall, 2011) seems to have left its mark on educators and students who no longer use this term to mean 'to abstain from.' Rather the unmoving statistics of abstinence education outcomes (Huelskamp, \& Catalano, 2018; Stanger-Hall \& Hall, 2011; Thomas-Deveaux, 2018; Zalaznick, 2017) lead to replacing abstinence with avoidance.

With avoidance, much of the abstinence principle is the same. Students understand that when it comes to both sexual and digital interaction it is better to simply avoid risky behavior, and based on the emphasis of social consequences, sexting is taught to be a high-risk behavior. However, there is a difference. Abstinence education is deeply rooted in concerns of preserving morality (Baker, Smith, \& Stoss, 2015). When it comes to sexting, avoidance is not a holistically inappropriate message for adolescents. Sexting does have many negative outcomes among this demographic (Drouin, Coupe, \& Temple, 2017; Lenhart 2009; 705 ILCS § 405), but these concerns are not specifically addressed. Rather, the focus is an "at all costs" avoidance message that still withholds much of the valuable, specific information from young adults. This limited 
information may be due to the perception that teenagers are too young to know or too reckless to be trusted (Elliott, 2012), or it could be closely tied to the casual approach that educators have when it comes to teaching on this topic.

Casual Approach to Education. As much as these preceding themes stood out within sexting education, from a broad view of school education and everything students are taught related to sex education and digital literacy education, sexting is seen as rather insignificant. The topic is approached casually by teachers and not taken seriously by students. But, this was not surprising. Moral panic over teen sexuality has been ongoing (Eversman \& Bird, 2017; GresleFavier, 2012) and persistently effective in suppressing even the discussion of teen sexual activity (Mitchell, 2014). Thus, merely glossing over a new outlet for adolescent sexuality aligns with historical patterns of societal approach to teens and sex and information.

The alternative motivation for this casual approach to sexting curriculum is that educators are ill-equipped to effectively teach on this topic. The high amount of outsourcing to videos or guest speakers for sexting information suggests that this might be an area that lacks classroom expertise, which I do not intend to be a poor reflection on the instructors. Afterall, sexting is only a recently growing trend (Lee, 2018; Madigan, Ly, Rash, Van Ouytsel, \& Temple, 2018). However, this does suggest that the entirety of this project is meaningful for helping educators understand the metaphorical ripples that are important to sexting education, which is then increasingly relevant when considering the potential for sexting to be a mandated educational topic (HB4007) and student's desire for increased sexting education.

Desire for Increased Education. Above all else, I was intrigued to hear students express that their current sexting education is not enough. Students are of the attitude that the messages of social consequences, self-responsibility, avoidance, and the casual approach to of all this are 
insufficient for affecting adolescent learning. As much as they hear about trends like 'send nudes' (Maycolacerda, 2010) and are prompted towards romantic experience development in the digital space ("Lessons in Love," 2017), they realize that they are not well informed for these interactions. And, this brings us full circle to the perpetual significance of this project: we throw students the keys to the car without teaching them how to drive. We push for technology adoption but do not first spend time learning and teaching about this digital space (Postman, 1985).

\section{Implications of Findings}

Innumerable confusions and a profound feeling of despair invariably emerge in periods of great technological and cultural transitions. Our 'Age of Anxiety' is, in great part, the result of trying to do today's job with yesterday's tools - with yesterday's concepts (McLuhan, 1967, p. 8).

Throughout this project I have captained us through the waves that are spurned by the technological interaction of sexting. Now, we zoom back out to gain perspective on the entirety of this media environment. Confusion in this changing digital age and negativity towards teenage sexting are largely due to educational mishaps, which are not advancing with shifts in digital sexual interaction. Students transition to new practices for romantic experiences while education continues to function with yesterday's concepts. The findings of this project have two resounding implications: educational impropriety and impending cultural stigmatization.

Education related to adolescent sexting does not encapsulate the many facets of mediated sexual interaction. Rather, the curriculum and resulting student understanding is far too similar to that of the old approach of abstinence education. Here, students are made the single, responsible party and instructed to avoid any illicit interaction online. But, in an environment where privately 
made sexual advances are increasingly normative for adolescent romantic experiences (Lee, 2018; Thomas, 2018), these educational messages are not sufficient. This is blatantly obvious in the resounding negative associations attached to just about any adolescent interaction that is sexual or digital. Now, more than ever, it is apparent that we cannot passively ask students to not participate online. In fact, it has recently become our only option. We must teach young adults about both positive and negative utilities of technological interaction, and this includes sexting that is both image oriented and text oriented.

A focus on the image was consistent across existing literature and curriculum. Any curricular or legal mention of sexting simultaneously included terms like 'explicit photos' or 'embarrassing pictures.' Even I approached this study within an image-centric framework through operationalizing sexting as the transmission of sexually suggestive or explicit images. However, multiple students brought up sexting as a function of text (not texting but typed/written text). Students defined sexting as also including sexual text. This implies that the cultural obsession with the image, particularly the sexual image, is shifting. Perhaps, the degree to which adolescents are encircled within visual media now operationalizes the text to be novel. Or, perhaps the heightened use of emojis allows for sexual images to be embedded as part of text rather than a separate entity. Regardless, this finding means that sexting as text cannot be neglected from the curriculum or future study.

Additionally, the cultural stigmatization attached to young adults who sext is unrelenting and unnecessary. The legal implications of distributing explicit images between minors are harsh. I do not wish to downplay the heinous nature of child pornography, but I must point out the application of this term across an environment that affords students this sort of interaction, and ill equips teens for these interactions, is an application that is too broad. The enduring 
criminal code mistakes the normative adolescent romantic experience of sexting for malicious child pornography. Forwarding of sexts or receiving unwanted sexts does blur this legal line, but those applying the law, administratively or legally, should be reserved room for this decision rather than implementing a zero-tolerance rule that was originally written to apply to a physical, not digital, age.

Likewise, when the existing curricula suggest that a corrupted reputation is of upmost concern for technological interaction consequence, stigmatization of sexting is encouraged. Social status is already of heightened concern among teens. An increased orientation towards social judgement of peers who sext is unnecessary fuel for the comparison fire that exists during this social formidable time. This message from educators feeds student's belief that peers who sext are rightfully outcast. If the legal system is not marking these students as felons, peers too often take it up themselves to distance other teens from social circles. The lack of resource-laden curriculum which stigmatizes teen sexting is disheartening when it comes to educational messages about sexting, so it is no wonder that McLuhan suggests "a profound feeling of despair ... in periods of great technological and cultural transition" (1967, p. 8). However, as an exploratory study, there is room for continued application of these findings to produce positive growth for educational messages of sexting to promote better understanding of the technological interaction afforded to students.

\section{Practical Applications}

The older training of observation has become quite irrelevant in this new time, because it is based on psychological responses and concepts conditioned by the former technology (McLuhan, 1967, p. 8). 
If this project brings about only one thing, I insist on that result being a conscious confrontation with the development of sexting education for adolescents. The existing curriculum is not enough to communicate the entire picture of teenage digital sexual interaction in a highly consequential environment, and students recognize this misfortune. We've given students the keys to the car, now we must teach them to drive, which includes everything from handling the car, or the technological interaction, and the rules of the road, or the policy associated with underage sexting. The following offers suggestions for increased adolescent sexting education, informed by the findings of this study, to produce education about sexting that is relevant to new technological interaction. By communicating a holistic understanding of sexting, allocating increased sexting resources, and specifically teaching digital literacy skills, students will be more equipped to 'drive' in the digital age.

Sexting education needs to be more inclusive of all contributing factors for and outcomes of sexting. The negative effects are rampant, but new education should not orient on these fear appeals. Rather, it should allow a space for a realistic perspective on the policy and social consequences while recognizing that there many aspects to adolescent sexting. Teachers should start by covering basics and define sexting, being sure to include various exchanges that can be categorized as sexting. By offering a fact based, multi-perspective curriculum, students will be better equipped to see all of the 'ripples' that are influenced by their digital sexual interactions. Continual negative messages in education only perpetuates scoffing attitudes from both educators who treat it too casually or negatively and from students who scorn peers for not totally avoiding sexting. Teachers should look to incorporate positively focused education about supporting peers who are sexting and offer factual information about when sexting could be beneficial to encourage students towards healthy relational development. 
Likewise, new sexting education should be inundated with resources for students who have sent or received sexts. Teens need to be empowered to knowledgably interact across the digital tools afforded to them. The proposed legislation in Illinois (HB4007) attempts to mandate coverage of resources by requiring educators to promote "the identification of individuals in school ... or in the community ... who may be contacted for assistance with issues, concerns, or problems" (p. 6). However, a major barrier to this empowerment is the harsh punishment that students could face when reporting their sexting interactions. Mandated reporters, such a teachers and school counselors, are required by law to report to authorities any illegal or unsafe action disclosed by a minor, particularly the distribution of child pornography. Failure to report sexting by minors to law enforcement or prescribed tip lines faces personal criminal charges (Abused and Neglected Child Reporting Act, 2019). This hinders student's ability to open express anything related to their engagement in sexting. Thus, the first step is to provide a safe space for students to get help from knowledgeable professionals without facing a potential felony. A change in school and state law that does not pursue these students as criminals is imperative for the ongoing success of such a space. Then, teachers and instructional designers should build curriculum that includes both global and local resources for reporting unwanted sharing of sexts or other online harassment related to sexts. Students who want to seek advice about sexting relationships should be directed to an individual with the capacity to appropriately respond.

Along these same lines, instructors should be supported in developing their understanding of digital literacy. The integration of digital literacy education into a health or sex-ed course is not enough to equip young adults for profound development of these necessary skills. Educational institutions should consider how digital literacy can be taught as a stand-alone course or copiously outlined as functional education across numerous subjects. Over and over I 
have discussed how when it comes to digital technology, we too often throw adolescents the keys to the car without teaching them to drive. Simply pushing coverage of cyberbullying and sexting as a subtopic in one course curriculum is not 'teaching students how to drive' but hoping they pick up these digital interaction skills from merely riding along. While students may seem to have a better grasp on digital functions, they lack critical skills for communicating that must be taught by well-informed instructors.

These suggestions for sexting instruction suggest a reform in education. Digital tools for communicating are inclusive to the point that teaching as always taught is no longer sufficient. Students cannot just sit back and observe teachings about sexting while immersed in an environment that contributes to this activity. Instead, education much be totally rethought to be encouraging, empowering, and intentional so that students are expert in their own technological interaction.

\section{Limitations and Future Research}

This study is well versed in theory and research so that it contributes substantially to the related body of work. However, there are limitations that should be recognized to optimize growth for future study. The first limitation is the broad environment wherein adolescent sexting takes place. I chose to pursue educational messages about sexting, but this is merely one of many influential, compounded contexts related to young adults and messages about sexting. Ongoing work might seek to isolate other areas of media or interpersonal relationships that contribute to teenager's attitudes about and engagement in sexting.

Another limit is the recruitment process. Due to time constraints, it was not possible to access students through public schools. The convenience sample restricted the scope of the recruitment message. Likewise, the process for conducting research with a protected population 
required the collection of parent permission whilst maintaining optimal confidentially. This meant that after the parent filed the permission form, it was up to the parent/guardian to pass along the interview link to their child, and I had no information with which to contact the student directly. Also, the online interview process appeared to be confusing to many students who did not show up online for their scheduled interview times.

In the future, with more time to complete a similar project, researchers should consider working with public schools to gather student participants. Ideally, students would take home and return a physical parent consent form and then have a scheduled time to complete an online interview during a free period, study hall, or lunch hour. This would enable greater confidentially or even anonymity for student participants who are recruited by a mediating source from their school. Additionally, researchers should consider how locational differences and impending cultural beliefs implicate the results of a similar study. This likewise includes access to curriculum. Certain school districts in many areas may lack resources for implementing sexting education in existing curricula, and researchers must be mindful of this variation when collecting educational materials.

Thus, further work on adolescent sexting education should focus on specific resource needs for educators or curriculum designers. Perhaps, with more information about sexting and sexting education, these individuals would be equipped to develop educational materials that empower young adult learners. Many students expressed their own thoughts about what new sexting education should include, so further research needs to continue equipping student voice for building relevant and effective sexting education. When adolescents are the interactants in this technological space and the intended recipients of related education, it is imperative that they be offered a voice in determining the educational messages. Without the student perspective, 
new curriculum design has the potential to yield a classroom instruction that has no relevance to students and inevitably fails them in their sexting education.

\section{Conclusion}

The medium, or process, of our time - electric technology - is reshaping and restructuring patterns of social interdependence and every aspect of our personal life. It is forcing us to reconsider and reevaluate practically every thought, every action, and every institution formerly taken for granted. Everything is changing (McLuhan, 1967, p. 8).

This study serves as an exploratory look at sexting education for adolescents. It highlights the prominent messages about sexting from existing curriculum and student understanding. These messages emphasis social consequences, self-responsibility, avoidance, casual education, and a need for increased education. Together, from integrated digital literacy and sexual education courses, students form negative attitudes about sexting and sexting participants. This approach is far too similar to abstinence only education and instills fear related to zero-tolerance policies applied to students who sext.

The findings of this study, in light of this project's media ecology approach, suggest that new education is necessary for students to be appropriately equipped for interaction in the digital age. As McLuhan suggests, because of recently introduced technological interaction, everything is changing. We realize that it is not the technology itself that poses dangers, but that these digital tools encapsulate human interaction to a degree far greater than previously experienced. Sexting is a prime context to explore how thought, action, and institution are shifting to create contentious spaces that leave students ill-equipped to understand digital sexual interaction. To best educate students about this new technological interaction, updated sexting instruction should 
be designed to promote resources for students who sext and destigmatize their digital engagement. Now that these two interfaces, sexual communication and digital communication, collide as one technological interaction, it is no longer applicable for sexting curriculum to be oriented around tools and concepts of the past. Fear oriented messages related to bullying and social out-casting should be left out of new education to be replaced by a holistic discussion of accurate policy consequences for sexting between minors. Above all, students must be central to the design of educational messages about sexting. Policymakers, educators, and researchers should look for means to empower student voice as expert in determining resource and instructional needs. Afterall, it is the young who instinctively understand the unfolding electronic drama (McLuhan, 1967) that is adolescent sexting. Therefore, relevant, student-centered education is the necessary, practical means to support adolescent sexting interaction in this new digital age wherein everything is changing. 


\section{REFERENCES}

Abused and Neglected Child Reporting Act, ILCS § 325 (2019).

Adler, P. A. \& Adler, P. (2012). Expert voices. In S. E. Baker \& R. Edwards (Eds.), How many qualitative interviews is enough? Expert voices and early career reflections on sampling and cases in qualitative research (8-11). Retrieved from http://eprints.ncrm.ac.uk/2273/4/how_many_interviews.pdf

Anderson, M. \& Jiang, J. (2018). Teens, social media \& technology 2018. Pew Research Center. Retrieved from https://www.pewinternet.org/2018/05/31/teens-social-media-technology$2018 /$

Angelides, S. (2012). The 'second sexual revolution,' moral panic, and the evasion of teenage sexual subjectivity. Women's History Review, 21(5), 831-847.

https://doi.org/10.1080/09612025.2012.658169

Aubrey, J. S. \& Smith, S. E. (2016). The impact of exposure to sexually oriented media on endorsement of hookup culture: A panel study of first-year college students. Mass Communication and Society, 19, 74-101.

https://doi.org/10.1080/15205436.2015.1070875

Aufderheide, P. \& Firestone, C. (1993). Media literacy: A report of the national leadership conference on media literacy. Queenstown, MD: Aspen Institute.

Baker, C., \& Carreño, P. (2016). Understanding the role of technology in adolescent dating and dating violence. Journal of Child \& Family Studies, 25(1), 308-320. https://doi.org/10.1007/s10826-015-0196-5 
Baker, J. O., Smith, K. K., \& Stoss, Y. A. (2015). Theism, secularism, and sexual education in the United States. Sexuality Research and Social Policy, 12(3), 236-247. https://doi.org/10.1007/s13178-015-0187-8

Barth, R. (2005). Sex education in the public schools. Virtual Mentor, 7(10), 701-704. https://doi.org/10.1001/virtualmentor.2005.7.10.msoc2-0510.

Bassett, R., Beagan, B. L., Ristovski-Slijepcevic, S., \& Chapman, G. E. (2008). The methodological challenges of interviewing teenagers as research participants. Journal of Adolescent Research, 23(2), 119-131. https://doi.org/10.1177/0743558407310733

Beyers, E. S., O’Sullivan, L. F., \& Brotto, L. A. (2016). Time out from sex or romance: Sexually experienced adolescents' decisions to purposefully avoid sexual activity or romantic relationships. Journal of Youth \& Adolescence, 45(5), 831-845. https://doi.org/10.1007/s10964-016-0447-9

Bradford, S. (2018). Teenagers, stop asking for nude photos. The New York Times. Retrieved from https://www.nytimes.com/2018/01/02/well/family/teenagers-stop-asking-for-nudephotos.html

Brewitt-Taylor, S. (2017). Christianity and the invention of the sexual revolution in Britain, 1963-1967. The Historical Journal, 60(2). https://doi.org/10.1017/s0018246x1600011x

Braun, V. \& Clarke, V. (2012). Thematic Analysis. In H. Cooper, P. M. Camic, D. L. Long, A. T. Panter, D. Rindskopg, \& K. J. Sher (Eds.), APA handbook of research methods in psychology, Vol. 2. Research designs: Quantitative, qualitative, neuropsychological, and biological, (57-71). Washington, DC, US: American Psychological Association. https://doi.org/10.1037/13620-004 
Burnett, A., Matterns, J. L., Herakova, L.L., Kahl, D. H., Tobola, C., \& Bornsen, S. E. (2009). Communicating/muting date rape: A co-cultural theoretical analysis of communication factors related to rape culture on a college campus. Journal of Applied Communication Research, 37(4), 465-485.

Center for Disease Control and Prevention. (2012). Health education curriculum analysis tool (HECAT). Retrieved from https://www.cdc.gov/healthyyouth/hecat/index.htm

Center for Disease Control and Prevention. (2017). Percentage of high school students who ever had sexual intercourse, by sex, race/ethnicity, grade, sexual identity, and sex of sexual contacts* - United States, Youth Risk Behavior Survey, 2017 [Data File]. Retrieved from https://www.cdc.gov/healthyyouth/data/yrbs/2017_tables/sexual_behaviors.htm\#t133_do wn

Center for Disease Control and Prevention. (2019). Characteristics of Effective Health Education Curriculum. Retrieved from https://www.cdc.gov/healthyschools/sher/characteristics/index.htm

Choukas-Bradley, S., Goldberg, S. K., Widman, L., Reese, B. M., \& Halpern, C. T. (2015). Demographic and developmental differences in the content and sequence of adolescents' ideal romantic relationship behaviors. Journal of Adolescence, 45, 112-126. https://doi.org/10.1016/j.adolescence.2015.08.019

Christakis, E. (2017). The war on public schools. Atlantic, 320(3), 15-18, Retrieved from https://search-ebscohostcom.libproxy.lib.ilstu.edu/login.aspx?direct=true \&db=f5h\&AN=125092118\&site=edslive $\&$ scop $=$ site 
Collins, W. A., Welsh, D. P., \& Furman, W. (2009). Adolescent romantic relationships. Annual Review of Psychology, 60, 631-652. https://doi.org/10.1146/annurev.psych.60.110707.163459

Coming of Age: Adolescent Health. (2019). Retrieved from https://www.who.int/healthtopics/adolescents/coming-of-age-adolescent-health

Culkin, J. (1967 March 18). A schoolman's guide to Marshall McLuhan. Saturday Review, 51$53,70-72$.

D’Amato, S. (2009). Modern romance. Teen Vogue. Retrieved from https://www.teenvogue.com/story/teens-talk-about-sex-and-hooking-up

Denzin, N. K. (2012). Triangulation 2.0*. Journal of Mixed Methods Research, 6(2), 80-88. https://doi.org/10.1177/1558689812437186

Dewar, J. A. (1998). The information age and the printing press: Looking backward to see ahead. Retrieved from https://www.rand.org.content/dam/rand/pubs/papers/2005/P8014.pdf

Doring, N. (2014). Consensual sexting among adolescents: Risk prevention through abstinence education or safer sexting? Cyberpsychology, 8(1), 1-18. https://doi.org/10.5817/CP20140109

Drouin, M., Coupe, M., \& Temple, J. R. (2017). Is sexting good for your relationship? It depends.... Computers in Human Behavior, 75, 749-756. https://doi.org/10.1016/j.chb.2017.06.018

Elliott, S. (2012). Parents' constructions of teen sexuality: Sex panics, contradictory discourses, and social inequality. Symbolic Interaction, 33(2), 191-212. https://doi.org/10.1525/si.2010.33.2.191 
Eversman, M. H., \& Bird, J. D. P. (2017). Moral panic and social justice: A guide for analyzing social problems. Social Work, 62(1), 29-36. https://doi.org/10.1093/sw/sww068

Eyal, K., Kunkel, D., Biely, E. N., \& Finnerty, K. L. (2007). Sexual socialization messages on television programs most popular among teens. Journal of Broadcasting \& Electronic Media, 51(2), 316-336. https://doi.org/10.1080/08838150701304969

Flick, U. (2004). Triangulation in qualitative research. In U. Flick, E. Kardorff, I. Steinke (Eds.), A companion to qualitative research, (178-183). London, UK: SAGE Publications.

Foreva, B. (2007, June 06). hookup. Definition posted to https://www.urbandictionary.com/define.php?term=hookup

Fortenberry, J. D. (2013). Sexual development in adolescents. Handbook of Child and Adolescent Sexuality, 171-192. https://doi.org/10.1016/B978-0-12-387759-8.00007-6

Furman, W. (2018). The romantic relationships of youth. In W. M. Bukowski, B. P. Laursen, \& K. H. Rudin (Eds.), Handbook of Peer Interactions, Relationships, and Groups, Second Edition (410-428). New York: The Guilford Press. Retrieved from https://searchebscohost-com.libproxy.lib.ilstu.edu/login.aspx?direct $=$ true $\& \mathrm{db}=$ nlebk\&AN $=1723011 \&$ site $=$ eds-live $\&$ scope $=$ site

Garcia, J. R., Reiber, C., Massey, S. G., \& Merriwether, A. M. (2013). Sexual hook-up culture: With more emerging adults having casual sex, researchers are exploring psychological consequences of such encounters. American Psychological Association (44)2.

Gewirtz-Meydan, A., Mitchell, K. J., \& Rothman, E. F. (2018). What do kids think about sexting? Computers in Human Behavior, 86, 256-265. https://doi.org/10.1016/j.chb.2018.04.007 
Guba, E. G. (1978). Toward a methodology of naturalistic inquiry in educational evaluation. Los Angeles, CA: Center for the Study of Evaluation.

Gubrium, J. F. \& Holstein, J. A. (2003). From the individual interview to the interview society. In J. F. Gubrium \& J. A. Holstein (Eds.), Postmodern interviewing (21-49). Thousand Oaks, CA: Sage Publications, Inc.

Greslé-Favier, C. (2012). The legacy of abstinence-only discourses and the pace of pleasure in US discourses on teenage sexuality. Sex Education, 10(4), 413-422. https://doi.org/10.1080/14681811.2010.51098

Haberland, N. \& Rogow, D. (2015). Sexuality education: Emerging trends in evidence and practice. Journal of Adolescent Health, 56(1), S15-S21. https://doi.org/10.1016/j.jadohealth.2014.08.013

Hannafin, M. J., Hill, J. R., Land, S. M., \& Lee, E. (2012). Student-centered, open learning environments: Research, theory, and practice. In J. M. Spector, M. D. Merrill, J. Elen, \& J. Bishop (Eds.), Handbook of research on educational communications and technology (pp. 641-651). Springer.

Helpern, J., Ferraro, T., Werder, C., \& Mason, N. (2017). Let's talk about sex. Teen Vogue, 19(1). 108. Retrieved from https://search-ebscohostcom.libproxy.lib.ilstu.edu/login.aspx?direct=true $\& d b=f 5 h \& A N=121212525 \&$ site $=$ edslive\&scope $=$ site

Herman, J. (2010). Sexting: It's no joke, it's a crime. Illinois Bar Journal, 98(4), 192-200. Retrieved from https://www.isba.org/ibj/2010/04/sextingitsnojokeitsacrime Hills, R. (2014). What every generation gets wrong about sex. Time. Retrieved from https://time.com/3611781/sexual-revolution-revisited/. 
Hobbs, R. (2004). Media literacy, general semantics, and K-12 education. ETC a Review of General Semantics, 61, 24-28. Retrieved from https://search-ebscohostcom.libproxy.lib.ilstu.edu/login.aspx?direct=true $\& d b=f 5 h \& A N=12965336 \&$ site $=$ edslive $\&$ scope $=$ site

Hobbs, R. (2017). Teaching and learning in a post-truth world: It's time for schools to upgrade and reinvest in media literacy lessons. Educational Leadership, 75(3), 26-31. Retrieved from https://search-ebscohostcom.lib.ilstu.edu/login.aspx?direct $=$ true $\& d b=u l h \& A N=125935931 \&$ stie $=$ edslive $\&$ scope $=$ site

Holman, A. \& Sillars, A. (2012). Talk about "hooking up": The influence of college student social networks on nonrelationship sex. Health Communication, 27(2), 205-216. https://doi.org/10.1080/10410236.2011.575540

Holstein, J. A. \& Gubrium, J. F. (2003). Active interviewing. In J. F. Gubrium \& J. A. Holstein (Eds.), Postmodern interviewing (67-80). Thousand Oaks, CA: Sage Publications, Inc.

Hsieh, H. \& Shannon, S. E. (2005). Three approaches to qualitative content analysis. Qualitative Health Research, 15(9), 1277-1288. https://doi.org/10.1177/1049732305276687

Huelskamp, A. C., \& Catalano, H. P. (2018). Lessons learned from implementation and evaluation of an evidence-based sex education pilot program for minority adolescent females. American Journal of Health Studies, 33(4), 196-205. Retrieved from https://search-ebscohostcom.libproxy.lib.ilstu.edu/login.aspx direct $=$ true $\& d b=c 9 h \& A N=135580677 \&$ site $=$ edslive $\&$ scope $=$ site 
Humphrey, W. A. (2016). Let's talk about sex: Legislating and educating on the Affirmative Consent Standard. University of San Francisco Law Review, 50(1), 35-74. Retrieved from https://search-ebscohostcom.libproxy.lib.ilstu.edu/login.aspx?direct=true $\& \mathrm{db}=$ ebshol\&AN=edschol.hein.journals .usflr50.6\&site $=$ eds-live $\&$ scope $=$ site

Illinois State Board of Education. (n.d.). School Health Issues. Retrieved from https://www.isbe.net/Pages/School-Health-Issues.aspx

ISTE. (2016). ISTE Standards for Students. Retrieved from https://www.iste.org/standards/forstudents

Jacob, S. A. \& Furgerson, S. P. (2012). Writing interview protocols and conducting interviews: Tips for students new to the field of qualitative research. The Qualitative Report, 17 (42), 1-10. Retrieved from http://nsuworks.nova.edu/cgi/viewcontent.cgi?article=1718\&context=tqr/

Jensen, K. (Ed.). (2002). A handbook of media and communication research: Qualitative and quantitative methodologies. London: Routledge.

Julian, K. (2018). The sex recession. Atlantic, 322(5), 78-94. Retrieved from https://search.ebscohost.com/login.aspx?direct=true\&db=f5h\&AN=132925579\&site=eds -live\&scope $=$ site

Kesler, T., Tinio, P. P. L., \& Nolan, B. T. (2016). What's our position? A critical media literacy study of popular culture websites with eighth-grade special education students. Reading \& Writing Quarterly, 32(1), 1-26. https://doi.org/10.1080/10573569.2013.857976

Kerner, I. (2013). Young adults and a hookup culture. CNN. Retrieved from https://www.cnn.com/2013/05/16/health/kerner-hookup-culture/index.html 
Kids \& Tech: The Evolution of Today's Digital Natives. (2016). Retrieved from http://influencecentral.com/kids-tech-the-evolution-of-todays-digital-natives/

Kohn, A. (1997). How not to teach values. Education Digest, 62, 12-17. Retrieved from https://search-ebscohostcom.libproxy.lib.ilstu.edu/login.aspx?direct=true \&db=eft\&AN=503567827\&site=edslive \&scope $=$ site

Kubica, R, (2006). Let's talk about sex: School surveys and parents' fundamental right to make decisions concerning the upbringing of their children. Villanova Law Review, 51(5), 1085-1106. Retrieved from https://search-ebsohostcom.libproxy.lib.ilstu.edu/login.aspx?direct=true $\& \mathrm{db}=$ edshol\&AN=edshol.hein.journals. vllalr51.51\&site $=$ eds-live \&scope $=$ site

Lauricella, A., Cingel, D., Blackwell, C., Wartella, E., \& Conway, A (2014). The mobile generation: Youth and adolescent ownership and use of new media. Communication Research Reports, 31(4), 357-364. https://doi.org/10.1080/08824096.2014.963221

Leary, M. (2010). Sexting or self-produced child pornography? The dialogue continues structured prosecutorial discretion within a multidisciplinary response. Virginia Journal of Social Policy and the Law, 17(13), 486-566. Retrieved from https://ssrn.com/abstract $=1657007$

Lee, B. Y. (2018). Here is how much sexting among teens has increased. Retrieved from https://www.forbes.com/sites/brucelee/2018/09/08/here-is-how-much-sexting-amongteens-has-increased/\#327a4f3a36f1 
Lee, C. M. \& Taylor, M. J. (2013). Moral education trends over 40 years: A content analysis of the Journal of Moral Education (1971-2011). Journal of Moral Education, 42(4), 399429. https://doi.org/10.1080/03057240.2013.832666

Lenhart, A. (2009). Teens and sexting: How and why minor teens are sending sexually suggestive nude or nearly nude images via text messaging. Pew Research Center. Retrieved from https://www.pewinternet.org/2009/12/15/teens-and-sexting/

Lenhart, A. (2012). Teens, smartphones, and texting. Pew Research Center. Retrieved from https://www.fitsnews.com/wpcontent/uploads/2012/03/PIP_Teens_Smartphones_and_Texting.pdf

Lessons in Love for Generation Snapchat. (2017). Retrieved from https://www.npr.org/2017/11/22/565618299/lessons-in-love-for-generation-snapchat Lindlof, T. R. \& Taylor, B. C. (2019). Qualitative communication research methods. Thousand Oaks, CA: SAGE Publications, Inc.

Lincoln, Y. S., \& Guba, E. G. (1985). Naturalistic inquiry. Beverly Hills, CA: Sage Publications. Lunceford, B. (2010). Sex in the digital age: Media ecology and Megan's law. Explorations in Media Ecology, 9(4), 239-244. Retrieved from https://search-ebscohostcom.libproxy.lib.ilstu.edu/login.aspx?direct=true \&db=edo\&AN=ejs25854485\&site=edslive $\&$ scope $=$ site

Macomb Community Unit School District Administrative Service Center. (2014). Health Curriculum Grades 6-12. Retrieved from https://macomb185.org/DocumentCenter/View/7003/Health-Curriculum-6-12?bidId= 
Macomb Community Unit School District. (2016). Guidelines for Investigating Sexting and Sextortion Allegations. Retrieved from https://macomb185.org/DocumentCenter/View/1001/policy7190AP6?bidId=

Madigan, S., Ly, A., Rash, C. L., Van Ouytsel, J., \& Temple, J. R. (2018). Prevalence of multiple forms of sexting behavior among youth: A systematic review and meta-analysis. JAMA Pediatrics, 172(4), 327-335. https://doi.org/10.1001/jamapediatrics.2017.5314

Madison, A. (2011). Real answers to your hookup Qs. Seventeen. Retrieved from https://www.seventeen.com/love/dating-advice/advice/a14598/hookup-questionsanswered/

Mann, C. \& Stewart, F. (2003). Internet interviewing. In J. F. Gubrium \& J. A. Holstein (Eds.), Postmodern interviewing (81-105). Thousand Oaks, CA: Sage Publications, Inc.

Manning, W. D., Longmore, M. A., Copp, J., \& Giordano, P. C. (2014). The complexities of adolescent dating and sexual relationships: Fluidity, meaning(s), and implications for young adults' well-being. New Directions for Child \& Adolescent Development, 2014(144), 53-69. https://doi.org//10.1002/cad.20060

Maycolacerda. (2015). Send nudes [Webpage]. Retrieved September 14, 2019 from https://knowyourmeme.com/memes/send-nudes

McClellan, B. E. (1999). Moral education in America: Schools and the shaping of character from colonial times to the present. New York, NY: Teacher's College Press.

McLuhan, M. (1964). Understanding media: The extensions of man. Cambridge, MA: MIT Press.

McLuhan, M. \& Fiore, Q. (1967). The Medium is the massage. Berkeley, CA: Gingko Press. 
Meyrowitz, J. (1985). No sense of place: The impact of electronic media on social behavior. New York: Oxford University Press.

Mitchell, K. J., Finkelhor, D., Jones, L. M., \& Wolack, J. (2012). Prevalence and characteristics of youth sexting: A national study. Pediatrics, 129(1), 13-20. Retrieved from https://search-ebscohostcom.libproxy.lib.ilstu.edu/login.aspx?direct=true $\& d b=$ edsbl\&AN=RN305148839\&site=e ds-live \&scope $=$ site

Mitchell, K. (2014). Let's talk about sex: How societal value evolution has redefined obscenity. Pace Intellectual Property, Sports \& Entertainment Law Forum, (2), 498-528. Retrieved from https://search-ebscohostcom.libproxy.lib.ilstu.edu/login.aspx?direct=true $\& d b=$ ebshol\&AN=heing.journals.pipself 4.19\&site $=$ eds-live $\&$ scope $=$ site

Montemurro, B., Bartasavich, J., \& Wintermute, L. (2015). Let's (not) talk about sex: The gender of sexual discourse. Sexuality \& Culture, 19(1), 139-156. Retrieved from http://search-ebscohostcome.libproxy.lib.ilstu.edu/login.aspx?direct=true \&db=edb\&AN=100631468\&site=edslive \&scope $=$ site

Monto, M. A., \& Carey, A. G. (2014). A new standard of sexual behavior? Are claims associated with the "hookup culture" supported by general social survey data? Journal of Sex Research, 51(6), 605-615. https://doi.org/10.1080/00224499.2014.906031

MTV. (2010). Sexting in America: When Privates Go Public. Retrieved from http://www.mtv.com/video-clips/ygmtvc/sexting-in-america-when-privates-go-publicpart-1 
Nasaw, D. (1979). Schooled to order: A social history of public schooling in the United States. Oxford, UK: Oxford University Press.

National Governors Association Center for Best Practices, Council of Chief State School Officers. (2010). Common core state standards: English language arts. Washington, D.C.: National Governors Association Center for Best Practices, Council of Chief State School Officers.

O'Connor, K., Drouin, M., Yergens, N., \& Newsham, G. (2017). Sexting legislation in the United States and abroad: A call for uniformity. International Journal of Cyber Criminology, 11(2), 218-245. https://doi.org/10.5281/zenodo.1037397

105 ILCS § 5/27-9.1 (2014).

Palmer, E. (2014). Teaching the core skills of listening \& speaking. Alexandria, VA: ASCD.

Pham, J. M. (2017). Beyond hookup culture: Current trends in the study of college student sex and where to next. Sociology Compass, 11(8), 1-11. https://doi.org/10.1111/soc4.12499

Playboy Interview: Marshall McLuhan (1969, March). Playboy, 26-27, 45, 55-56, 61, 63.

Postman, N. (1985). Amusing ourselves to death: Public discourse in the age of show business. New York: Penguin Books.

Postman, N. \& Paglia, C. (2007). Two cultures: Television versus print. In D. Crowley \& P. Heyer (Eds.), Communication in history: Technology, culture, society, 5th Ed. (283-295). Boston: Allyn \& Bacon.

Raghuram, N. (2019). Sex ed fails teens by ignoring sexting. Mashable. Retrieved from https://mashable.com/article/sexting-sex-ed/

Rogers, C. R. (1969). Freedom to learn. Columbus: Merrill. 
Rousmaniere, K., Dehli, K., \& Connick-Smith, N. (1997). Discipline, moral regulation, and schooling: A social history. New York, NY: Garland Publishing, Inc.

Ryan, K. \& Hood, L. K. (2004). Guarding the castle and opening the gates. Qualitative Inquiry, 10(1), 79-95. https://doi.org/10.1177/1077800403259583

Santelli, J. S., Kantor, L. M., Grilo, S. A., Speizer, I. S., Lindberg, L. D., Heitel, J., Schalet, A. T., Lyon, M. E., Mason-Jones, A. J., McGovern, J. D., Heck, C. J., Rogers, J., \& Ott, M. A. (2017). Abstinence-only-until-marriage: An updated review of U.S. policies and programs and their impact. Journal of Adolescent Health, 61(3), 273-280. https://doi.org/10.1016/j.jadohealth.2017.05.031

Schalet, A. T. (2011). Not under my roof: Parents, teens and the culture of sex. Chicago: University of Chicago Press, 2011.

705 ILCS $\S 405 / 3-40$ (2015).

720 ILCS $\S 5 / 11-21(2016)$.

Sex-Negative. (2019). In Oxford Dictionary online. Retrieved from https://www.lexico.com/en/definition/sex-negative

Sex Positive Approaches with Adolescents. (2019). Adolescent Health Initiative. Retrieved from https://www.adolescenthealth.org/SAHM_Main/media/AM19/Handouts/Sex-PositivityResource-List-(002).pdf

Skiba, R., Reynolds, C. R., Graham, S., Sheras, P., Conoley, J. C., \& Garcia-Vasquez, E. (2006). Are zero tolerance policies effective in the schools? An evidentiary review and recommendations. APA Zero Tolerance Task Force Report, 1-140. Retrieved from http://www.abajournal.com/magazine/article/schools_start_to_rethink_zero_tolerance_po licies 
Social Security Act, $10 \S 510$ (1996).

Stanger-Hall, K. F., \& Hall, D. W. (2011) Abstinence-only education and teen pregnancy rates:

Why we need comprehensive sex education in the U. S. PLoS ONE, 6(10), 1-11. https://doi.org/10.137/journal.pone.0014658

Strassberg, D. S., McKinnon, R. K., Sustaíta, M. A., \& Rullo, J. (2010). Sexting by high school students: An exploratory and descriptive study. Archives of Sexual Behavior 42(1), 15-21. https://doi.org/10.1007/s10508-012-9969-8

Strate, L. (2004). A media ecology review. Communication Research Trends, 23(2). Retrieved from http://cscc.scu.edu/trends/v23/v23_2.pdf

Strate, L. (2017). Media ecology: An approach to understanding the human condition. New York, NY: Peter Lang Publishing.

Strauss, A. L., \& Corbin, J. M. (1998). Basics of qualitative research: Techniques and procedures for developing grounded theory ( 2 nd ed.). Thousand Oaks, CA: Sage Publications, Inc.

Teske, S. C. (2011). A study of zero tolerance policies in schools: A multi-integrated systems approach to improve outcomes for adolescents. Journal of Child and Adolescent Psychiatric Nursing, 24, 88-97. https://doi.org/10.1111/j.1744-6171.2011.00273.x

Thomas-Deveaux, A. (2018). The sexual miseducation of America. Cosmopolitan, 265(6), 132. Retrieved from https://search-ebscohostcom.libproxy.lib.ilstu.edu/login.aspx?direct=true $\& d b=f 5 h \& A N=132620686 \&$ site=edslive\&scope $=$ site 
Thomas, S. (2017). 'What should I do?': Yong women's reported dilemmas with nude photographs. Sexuality Research and Social Policy 15, 192-207. https://doi.org/10.1007/s13178-017-0310-0

United Nations Population Fund. (2014). UNFPA operational guidance for comprehensive sexuality education: A focus on human rights and gender. United Nations Population Fund. Retrieved from https://www.unfpa.org/sites/default/files/pubpdf/UNFPA $\% 20$ Operational $\% 20$ Guidance $\% 20$ for $\% 20$ CSE $\% 20$ Final\%20WEB\%20Version.pdf

Van Ouytsel, J., Van Gool, E., Walrave, M., Ponnet, K., \& Peeters, E. (2016). Exploring the role of social networking sites within adolescent romantic relationships and dating experiences. Computers in Human Behavior, 55, 76-86. https://doi.org/10.1016/j/chb.2015.08.-42

Vandewater, (2013). Ecological approaches to the study of media and children. In D. Lemish (Ed.), The Routledge international handbook of children, adolescents and media (pp. 4653). Oxon, United Kingdom: Routledge.

Wan, G., \& Gut, D. (2008). Media use by Chinese and U.S. secondary students: Implications for media literacy education. Theory Into Practice, 47(3), 178-185. https://doi.org/10.1080/00405840802153783

Ward, S. F. (2014). Schools start to rethink zero tolerance policies. ABA Journal. Retrieved from http://www.abajournal.com/magazine/article/schools_start_to_rethink_zero_tolerance_po licies

White, B. (2015). Scapegoat: John Dewey and the character education crisis. Journal of Moral Education, 44(2), 127-144. https://doi.org/10.1080/03057240.2015.1028911 
Wood, R. H. (2010). The first amendment implications of sexting at public schools: A quandary for administrators who intercept visual love notes. Journal of Law and Policy, 18(2), 701737. Retrieved from https://brooklynworks.brooklaw.edu/cgi/viewcontent.cgi?article=1123\&context=jlp

Wright, L. (2012). UNH education law expert: Zero tolerance is not the answer to sexting. UNH Today. Retrieved from https://scholars.unh.edu/new/3874

Zalaznick, M. (2017). Beyond the birds and bees. District Administration, 53(3), 47-49. Retrieved from https://search-ebscohostcom.libproxy.lib.ilstu.edu/login.aspx?direct=true \&db=f5h\&AN=121482326\&site=edslive $\&$ scope $=$ site 


\section{APPENDIX A: SOCIAL MEDIA RECRUITMENT MESSAGE}

Hello!

I am conducting a study for my master's thesis on messages about sexting from public school curriculum and what themes from these messages are used to form student attitudes about sexting. Do teachers convey any messages about sexting? What do students think about these messages? Do the themes of the messages form students' attitudes about sexting?

This research will hopefully help me to understand where there may be gaps in school instruction and teen digital communication use. I am conducting voluntary, confidential online interviews with students who are currently enrolled in a public high school in central Illinois. The interviews will be totally confidential and can be stopped at any time. By confidential, I mean that no personal information about the student will be collected before, during, or after the interview (more details about the study are included in following informed assent documents). Participants will use a private instant messaging platform to type their responses. These interviews will be no more than 30 minutes.

To participate, you or your child must be between the ages of 14-18 years old and be currently enrolled in a public high school in central Illinois. If you are younger than 18, a parent or guardian must first sign an informed assent document for you or your teenager to participate.

Please click the corresponding link to the participation document if you or your child is interested in participating or message me directly or email me at ametz@ilstu.edu.

My child is 14-17 years old, attends public high school, and would like to participate: https://illinoisstate.azl.qualtrics.com/jfe/form/SV_2r6IhJXt9CXVO97

I am 18 years old, attend public high school, and would like to participate: https://illinoisstate.azl.qualtrics.com/jfe/form/SV_5iDOHGgt7mckisR

Thank you for your help! 


\section{APPENDIX B: PARENTAL CONSENT FORM}

You are being asked to allow your child to participate in a research study conducted by Allison Metz under the direction of Dr. Lauren Bratslavsky from the School of Communication at Illinois State University. The purpose of this study is to understand the messages that high school students receive about sexting from public school curriculum and how these messages, if any, form student's attitudes about sexting.

\section{Why is your child being asked to participate?}

Your child has been asked to participate because he/she/they are currently enrolled in a public high school in central Illinois and are 14-17 years of age. Your child is ineligible to participate if they are enrolled in a special education program at their public school. Your child is ineligible to participate if they are located in the European Economic area when data is collected.

Their participation in this study is voluntary. Neither you nor your child will be penalized if either of you choose to skip parts of the study, not participate, or withdraw from the study at any time.

\section{What would your child do?}

If you choose to allow your child to participate in this study, they will be interviewed using a digital messaging system via the communication platform, Zoom. The researcher will ask a series of questions via instant messenger and participants will type their responses. The interview questions will ask students about the school instruction they have received from their sex-ed and digital training classes. They will also be asked questions about how their school instruction has formed their attitudes about sexting. Participants will not be asked anything about personal participation in sexting. In total, your child's involvement in this study will last approximately 30 minutes.

\section{Are any risks expected?}

Participants may feel uncomfortable talking about the sensitive issue of sexting. However, the interview questions will refrain from participants indicating any personal involvement in sexting and throughout the interview, your child will be reminded that they can chose to not respond to any questions they wish to not answer or end the interview early.

Additionally, throughout the course of the interview, the interviewer may indicate that sexting between minors in the state of Illinois is illegal. This education about sexting consequences is beneficial for participant learning; however, it may cause distress if underaged participants have engaged in sexting. To minimize this risk, the interview will close with a statement about where teenagers can go to access assistance with such concerns: PATH (Providing Access to Help) at 211 or 1-888-865-9903 or NAMI (National Alliance on Mental Health) at 1-800-950-6264.

\section{Will your child's information be protected?}

We will use all reasonable efforts to keep any provided personal information confidential. Your child's identifiers will not be associated with any of their responses. His/her/their school name will be changed on any transcripts or research analysis. Your child's responses will be kept in a password protected folder in the primary researcher's password protected computer. Information 
that may identify your child or potentially lead to reidentification will not be released to individuals that are not on the research team. The confidential interview responses will be analyzed for themes and used to further the study of messages about sexting in public education and will be used to complete the primary researcher's master's thesis. Again, no names of participants or other identifying features will be used in the research analysis document. However, when required by law or university policy, identifying information may be seen or copied by authorized individuals.

We need to make you aware that in certain research studies, it is our legal and ethical responsibility to report illegal activity associated with minors to appropriate authorities. However, we are not seeking this type of information in our study nor will your child be asked questions about these issues.

\section{Could your child's responses be used for other research?}

We will not use any identifiable information from your child in future research, but their deidentified information could be used for future research.

\section{Who will benefit from this study?}

The responses collected from your child will be incredibly beneficial to building future curriculum that aims to teach adolescents how to appropriately use digital communication. We see this research project as a foundational building block to real instructional development for effective technology training for teens.

Additionally, your child will personally benefit by being empowered to voice their experiences in public education and make a difference for future public-school instruction. Also, throughout the interview, your child will learn about the potential consequences of sexting, thus informing them about effective use of digital communication.

\section{Whom do you contact if you have any questions?}

If you have any questions about the research or wish to withdraw your child from the study, contact Allison Metz at ametz@ilstu.edu or Dr. Lauren Bratslavsky at 309-438-7977 or email lbrats1@ilstu.edu.

If you have any questions about your child's rights as a participant, or if you feel that your child has been placed at risk, contact the Illinois State University Research Ethics \& Compliance Office at (309) 438-5527 or IRB@ilstu.edu.

\section{Documentation of Consent}

By clicking next, you are indicating that you are 18 or older and willing to allow your child to participate in this study. After clicking next, you will be prompted to enter your personal email address to receive a scheduling link for the interview. You are asked to forward this link to your child so that they may participate in the online interview.

You can print this form for your records. 


\section{APPENDIX C: PARTICIPANT INFORMED ASSENT}

You are being asked to participate in a research study conducted by Allison Metz under the direction of Dr. Lauren Bratslavsky from the School of Communication at Illinois State University. The purpose of this study is to understand the messages that high school students receive about sexting from public school curriculum and what themes from these messages, if any, form student's attitudes about sexting.

\section{Why are you being asked to participate?}

You are being asked to participate because you are currently enrolled in a public high school in central Illinois and are 14-17 years of age. You are ineligible to participate if you are enrolled in a special education program at your public school. You are ineligible to participate if you are located in the European Economic area when data is collected.

Your participation in this study is voluntary. You will not be penalized if either you choose to not respond to parts of the interview, not participate, or end the interview at any time.

\section{What will you do?}

If you agree to participate in this study, you will be interviewed using a digital messaging system via the communication platform, Zoom. The researcher will ask a series of questions via a "chat" feature and you will type your responses. The interview questions will ask you about the school instruction that you have received from their sex-ed and digital training classes. You will also be asked questions about how this school instruction has formed your attitudes about sexting. You will not be asked anything about your personal participation in sexting. You should not indicate if you have engaged in sexting under the age of 18. In total, your involvement in this study will last approximately 30 minutes.

\section{Are any risks expected?}

You may feel uncomfortable talking about the sensitive issue of sexting. However, the interview questions will refrain from your indicating of any personal involvement in sexting and throughout the interview, you will be reminded that you can chose to not respond to any questions you don't want to answer, or you can end the interview early.

Additionally, throughout the course of the interview, the interviewer may indicate that sexting between minors in the state of Illinois is illegal. This education about sexting consequences is beneficial for your learning; however, it may cause you distress if you have engaged in sexting. If you feel distressed about this, you can contact the follow numbers to receive guidance: PATH (Providing Access to Help) at 211 or 1-888-865-9903 or NAMI (National Alliance on Mental Health) at 1-800-950-6264.

\section{Will your information be protected?}

We will use all reasonable efforts to keep any provided personal information confidential. Any identifiers will not be associated with any of your responses. Your school name will be changed on any transcripts or research analysis. Your responses will be kept in a password protected folder in the primary researcher's password protected computer. Information that may identify you or potentially lead to reidentification will not be released to individuals that are not on the 
research team. The confidential interview responses will be analyzed for themes and used to further the study of messages about sexting in public education and will be used to complete the primary researcher's master's thesis. Again, no names of participants or other identifying features will be used in the research analysis document.

However, when required by law or university policy, identifying information may be seen or copied by authorized individuals.

We need to make you aware that in certain research studies, it is our legal and ethical responsibility to report illegal activity associated with minors to appropriate authorities. However, we are not seeking this type of information in our study nor will you be asked questions about these issues.

\section{Could your responses be used for other research?}

We will not use any identifiable information from you in future research, but your deidentified information could be used for future research.

\section{Who will benefit from this study?}

The responses collected from you will be incredibly beneficial to building future curriculum that aims to teach adolescents how to appropriately use digital communication. We see this research project as a foundational building block to real instructional development for effective technology training for teens.

Additionally, you will personally benefit by being empowered to voice your experience in public education and make a difference for future public-school instruction. Also, throughout the interview, you will learn about the potential consequences of sexting, thus informing you about effective use of digital communication.

\section{Whom do you contact if you have any questions?}

If you have any questions about the research or wish to withdraw from the study, contact Allison Metz at ametz@ilstu.edu or Dr. Lauren Bratslavsky at 309-438-7977 or email lbratsl@ilstu.edu.

If you have any questions about your rights as a participant, or if you feel that you have been placed at risk, contact the Illinois State University Research Ethics \& Compliance Office at (309) 438-5527 orIRB@ilstu.edu.

\section{Documentation of Assent}

By clicking next, you are indicating that you are between the ages of 14-17, are currently enrolled in a public high school in central Illinois, and you voluntarily agree to be digitally interviewed for this study.

You can print this form for your records. 


\section{APPENDIX D: INTERVIEW PROTOCOL}

Thank you for agreeing to participate in my study on messages about sexting. I am going to ask you a series of open-ended questions about your school sex education, your school digital training, and the attitudes you have about sexting.

I'm going to ask you some questions today, and I would love for you to give me as much detail in your responses as you like. Everything you say will be confidential, which means I will not share any identifying information with anyone.

Do you have any questions about this?

Remember that you are more than welcome to end the interview at any time and you won't face any penalty for not completing the interview.

Are you okay with all of that?

What other questions do you have for me before we get started with some questions?

Okay. So, let's get started. First, I'd like to ask you just one background question:

1. What is your grade at school?

Excellent. Now let's chat about some of the things you may or may not have learned about is Sex-Ed in high school.

1. Can you start by telling me what you remember most from your sex-ed classes at school?

a. What kinds of things did they talk about?

b. How many days did you spend talking about sex?

2. What did your teacher in these classes tell you about sexting?

a. How would you define sexting?

3. What do you wish you would have talked about in your sex-ed classes?

4. Pretend for a minute that you have just been chosen as the new teacher for a health class and you have to teach sex-ed. What sorts of things would you teach your students?

a. What would you do differently from the class you were in as a student?

b. What would you do the same as your sex-ed teacher?

Great. Now, I'm going to move on to a different subject you may or may not have learned about in high school. I am going to ask you about some of the digital safety or online training your teachers have maybe taught you in school.

1. Has anyone at school every taught you how to interact with others online?

a. Tell me about what you remember most from your digital training classes?

i. What kinds of things did they talk about?

2. Did this teacher, or any other teacher, ever talk about sexting? 
a. What did they say about sexting?

3. What do you wish you would have learned about in your digital training classes?

4. Imagine you were the teacher for a class that taught your classmates about how to interact online. What would you teach them about?

Thank you. I just have a few more questions left. Your answers have been very helpful, so far. For the last few questions, I am going to ask you about your own attitudes about sexting. You can give me as much or as little information as you're comfortable with. Just remember, I am asking you about how you feel about sexting, so you don't need to tell me anything about sexting

1. What is your attitude about sexting?

2. What do you remember from school that shaped this attitude about sexting?

3. Imagine that your close friend told you that they were thinking about sending a sext. What would you say to them?

a. Would you give them any advice?

b. Why would you say that to your friend?

4. Do you think that your classmates know that it is illegal to sext if you are under the age of 18 ?

a. If so, how do you think they know this?

b. If not, who do you think should tell them?

5. Do you know what you school policy is for sexting?

a. If so, who told you about this?

b. If not, do you have any idea how to find this information? (Maybe someone you could ask?)

Well that wraps up all of the questions that $I$ have for you.

Is there anything else that you think I should know about sex-ed, digital training, or sexting that we haven't already talked about?

Do you have any other questions for me?

Alright, well thank you so much for all of the information you gave me. It has been very helpful. Please let me know if there is anything else you think I should know or if you have any follow up questions about our interview or my research. I am now sending you a link to a form that includes how you can contact me with any questions or concerns and also some phone numbers that you can call if you have any distress or concern about what we just discussed. Thank you so, so much for participating today. Your participation has been very helpful! 
Alright, well thank you so much for all of the information you gave me. It has been very helpful. Please let me know if there is anything else you think I should know or if you have any follow up questions about our interview or my research. I am now sending you a link to a form that includes how you can contact me with any questions or concerns and also some phone numbers that you can call if you have any distress or concern about what we just discussed. Thank you so, so much for participating today. Your participation has been very helpful!

https://illinoisstate.az1.qualtrics.com/jfe/form/SV_dncBgDlHNt7NlqZ 